\title{
Substitution of Wheat Flour by Local Cereals and Pulses Flour "An approach to overcome wheat gap in Egypt" 3- Balady Bread Quality
}

\author{
M. Abd El- Sattar Ahmed, ${ }^{*}$ Zeinab R. Atia $^{1}$ and, M.M El-Genbeihy ${ }^{2}$ \\ 1; Professor, Crop Science Dept., Fac.Agric. (El-Shatby), Alexandria University . \\ 2; Lecturer, Crop Science Dept., Fac.Agric. (El-Shatby), Alexandria University. (Zi- \\ nab.atia@alexu.edueg) \\ *; corresponding author. (Mohamed.A@alexu.edu.eg).
}

\begin{abstract}
The recent study included studying the possibility of substituting local cereals flours (rice, sorghum and naked barley) to local bread wheat cultivars. Adding fenugreek local pulse flour and imported soybean flour to improve characters of bread was also included. Separate experiments were carried out for each bread wheat variety. The studied local bread wheat cultivars were; Misr2, Giza 171 and Gemmiza 11.Row materials for local cereals, fenugreek and bread wheat cultivars were obtained from Agricultural Research center, Ministry of Agriculture, Giza, Egypt. Raising the level of rice flour substitution to $20 \%$ gave lower loaf diameter relative to $10 \%$ rice flour level $(20.22$ vs. $21.04 \mathrm{~cm}$ for 20 and $10 \%$ rice flour substitution levels, respectively). This might indicate an increase in dough elasticity (loaf shrunk). Also, the addition of $5 \%$ fenugreek flour to blend of $20 \%$ rice flour, gave substantial reduction in loaf diameter $(19.78 \mathrm{~cm})$. While, the least significant loaf diameter was expressed by the blend of $20 \%$ rice flour $+5 \%$ soybean flour $+75 \%$ wheat flour $(18.63 \mathrm{~cm})$.loaf diameter was significantly reduced when barley flour was blended to wheat flour at $10 \%$ level (high dough elasticity) (19.09 vs. $20.67 \mathrm{~cm}$ for wheat flour $+10 \%$ barley flour blend and full wheat flour, respectively). Additional substitution to wheat flour by $5 \%$ fenugreek flour reduced dough elasticity (larger loaf diameter) $(20.44 \mathrm{~cm})$. Meanwhile, $5 \%$ soybean flour substitution in wheat $+10 \%$ barley flour gave lower loaf diameter (higher elasticity) $(19.30 \mathrm{~cm}$ ). blends that contained $5 \%$ fenugreek $+5 \%$ soybean flours gave narrower loaf diameter in blends in Misr2 and in blends of Giza171, While, blends of Gimmeza11 flours besides fenugreek and soybean flours gave larger loaf diameter after baking. Blends of Misr2 wheat substituted with rice flour had heavy loaf weight over blends substituted with sorghum flour. While, the opposite was true with blends of Giza171 and Gimmeza11. Also, comparison between blends substituted with rice flour and those substituted by barley flour showed an increase in loaf weight after baking with barley flour with Misr2 cultivar. While, vas versa were noticed with Giza171 and Gimmeza11. Wheat flour blends with local cereals substitution and fenugreek flour versus those with soybean flour showed a superiority of the former in loaf weight after baking over the latter for Misr2 cultivar and a reduction for Giza171 and for Gimmeza11 cultivar.
\end{abstract}

Key words: Substitution, wheat flour, rice flour, sorghum flour, pulses flour, bread quality, loaf diameter, loaf weight.

\section{INTRODUCTION}

Among the cultivated cereals, wheat has a unique nourishment position. This simply goes to the type of starch it contains, it is content of protein, minerals, vitamins and fat (Ereifej et al., 2006). Dough produced from wheat flour different from those made from other cereals in their viscoelastic properties. The raised bread loaf is possible because the wheat kernel contain gluten, an elastic form of protein that trap minute bubbles of carbon dioxide when fermentation occurs in leavened dough causing the dough to rise (Popa et al., 2014).

Tanaka (1972), studied the influenced of rice flour substitute on the baking quality of wheat flour and the method to improve the rice bread quality were examined. The results were as follows; (1) the baking quality of wheat flour and also the loaf volume are reduced by substituting rice flour to which the use of surfactant is effective, (2) extension of the final proofing time and the use of $\alpha$-amylase are effective to increase the loaf volume and (3) it was better not to reduce too much the size of rice flour particle. Hadnađev et al. (2011) showed that, Flours from different raw materials were tested in order to investigate their ability to mimic wheat flour dough behavior during bread making and bread baking. Among tested alternative cereals (rice, corn), pseudo cereals (buckwheat, amaranth) and legumes (soybean). Rice and buckwheat flours expressed the most similar protein (water absorptions, stabilities and degrees of mechanical weakening) and starch (peak, minimum and setback torque) characteristics as wheat flour .Islam et al. (2011), reached that, bread volume decreased, whereas bread weight and moisture content increased with the increasing level of maize and brown rice flour. Also, Bread quality in respects of bread volume and crumb texture were improved by using $2.5 \%$ yeast, $5 \%$ sugar, $5 \%$ fat and $0.6 \%$ improver. Rai et al. (2012), determined proximate composition and pasting properties of raw materials, bread making quality and sensory qualities of breads produced from varying substitutions of rice flour and maize meal with wheat flour. They indicated that, the baking absorption was observed to increase with higher level of maize meal, but it decreased when level of rice 
flour was increased. Loaf weight (g) decreased with progressive increase in the proportion of maize meal but increased when rice flour incorporation was increased. Loaf volume, loaf height and specific volume decreased for progressively higher level of maize meal and rice flour. The sensory evaluation revealed that $25 \%$ replacement of wheat flour was found to be more acceptable than control sample. Khoshgozaran-Abras et al. (2014), indicated that, it was feasible to incorporate brown rice (BR) flour for baking Barbary flat bread; However, the threshold of BR flour addition should be $\leq 5 \%$. This is simply because, dough made from blend flour fortified with $5 \%$ BR flour, due to rheological evaluation, was strong and baked flat bread was highly ranked acceptable by panelists and remained fresher in comparison with other treatments by the end of storage.

Bhatt and Gupta (2015), prepared healthy bread, enriched with protein and fiber, from composite flours formulations, to evaluate nutritional, phytochemical activity, functional and physiochemical properties of the flours and breads. Composites flour prepared using whole grain flours of sorghum, chickpea, and buckwheat, sprouted barley and sprouted wheat blended with refined wheat flour and whole wheat flour, not only increased the nutritive value but also, the phytochemical characteristic of the bread. From the study, data revealed that, nutritionally and organoleptically accepted bread (BII) after baking showed high flavonoid content. The composite bread (B-II) also consisted high amount of fiber content which make it functional product good for diabetic people. The baking loss was found to be in the acceptable range. Sibanda et al. (2015) studied the effect of partial substitution of wheat flour with white grain sorghum flour on the rheological properties and bread making quality of the composites. Composite flours containing 10\%, 20\% and 30\% sorghum were analyzed for their physicochemical composition. Sorghum addition resulted in a decrease in bread volume with sorghum replacement of higher than $20 \%$. The incorporation of sorghum at $10 \%$ produces bread of similar quality to wheat flour. Vásquez et al. (2016), partially substituted wheat flour with sorghum (SF), oat (OF), or corn (CF) flours at the 2.5, 5, 7.5, and $10 \%$ levels. They found that low substitutions could considerably reduce the cost of raw materials and could nutritionally improve products with cereal blends. However, they added that it is necessary to evaluate any changes in bread characteristics.

Niffenegger (1964) showed that, the starch and proteins of barley and wheat flour behave differently. The starch of barley flour has less thickening capacity and less water absorption than wheat. The protein has less gluten-like strength. Baked products which are dependent on glutenlike strength are made less successfully from barley flour than from wheat flour. Appearance and flavor are usually affected by the addition of barley flour. Sollars and Rubenthaler (1971), reported the role of starch in three soft wheat flour tests studied using reconstituted flours. They showed that, reconstituted flour with barley starch proved very good for cakes and cookies and had viscosities close to this of flour with wheat starch. These results indicate that starch must have certain physical and chemical properties for satisfactory performance. Dhingar and Jood (2002), studied the physico-chemical and nutritional properties of cereal pulse blends for bread making. Supplementation of soy (full fat and defatted) and barley flours to wheat flour at 5, 10, 15 and $20 \%$ levels were studied. They found that, All the blends at $20 \%$ levels were found nutritionally superior, but breads prepared from them found organoleptically unacceptable. However, addition of $15 \%$ barley flour, $10 \%$ full fat soy flour, $10 \%$ defatted soy flour, $15 \%$ full fat soy flour+ barley flour and $15 \%$ defatted soy flour+ barley flour to wheat flour not only increased the total protein, glutelin (protein fraction), total lysine, dietary fibre and $\beta$ glucan contents of cereal-pulse blends for bread making, but, could also produce a product of acceptable quality. Hruskova et al. (2003), studied the improved effect of malt flour on the rheological properties of full dough system during the proofing, the oven spring, and the baking process. The influence of small amounts of malt flour on the proofing stability was significant. The increase was about $40 \%$ for both sets of flour. The proofing time was not prolonged as significantly as the dough elasticity in all samples. The dough behavior during oil baking in the oven rise tests was influenced by the addition of malt at an important level, similarly as the specific bread volume in the baking test, and they found the bread shape ratio increased insignificantly by the malt fortification. A significant correlation was obtained between the oven spring parameters and the baking test results, but as far as the maturograph characteristics are concerned, their relationship to the bread volume depends on flour quality. Dhingra and Jood (2004), studied the effect of supplementation on the functional, baking, and organoleptic characteristics of bread. They indicated that the bread volume decreased with increasing amount of non-wheat flour substitution. It may be concluded that the substitution of wheat flour with soybean and barley flour up to an amount equivalent to $10 \%$ of full-fat and defatted soy flour, $15 \%$ for barley flour, full-fat soy + barley flour and defatted soy + barley flour produced acceptable bread loaves with good organoleptic characteristics. Ereifej et al. (2006), suggested that, barley flour can be used to replace $30 \%$ to $45 \%$ of wheat flour in Balady bread loaves without adversely affecting the consumer acceptability of the bread. However, when increasing barley flour content beyond these limits, the resulting bread loaves are found to be harder, darker in color, and non- 
uniformly shaped; therefore, less acceptable bread. Sullivan et al. (2010), produced doughs and breads using pearled barley flour (PBF) in different ratios $(30,50,70$ and $100 \%)$ to wheat flour. A $100 \%$ wheat flour formulation was used as a control. They found that, a low protein content usually signifies a reduced baking quality, so this result would suggest that, the inclusion of barley flour into the bread formulation would decrease the quality of the resulting breads. Increasing the pearled barley flour concentration significantly decreased the volume of the breads. The results would indicate that, there is potential for a bread product containing up to $50 \%$ barley flour. Lin et al. (2012) illustrated the effect of barley on the mechanical properties of wheat flour dough, which was important for determining both the properties of the dough during processing and the quality of the end-product. They used steamed bread incorporated with barley flour at 10, 20 and 30\% substitution levels. They found that, increased levels of barley flour caused significant decreases in the specific volume, brightness, and whiteness index of steamed bread, as well as increases in hardness and chewiness. Hussein et al. (2013), focused on substituting a part of wheat flour (WF) with whole meal barley (WBF), gelatinized corn flour (GCF) and both of them in balady bread. It is found that, WF supplemented with WBF: GCF (30:15\%) did not affected technological quality of balady bread and improved its nutritive values. Mariotti et al. (2014), showed that, the barley sourdoughs investigated could be used to obtain barley bread with enhanced nutritional value. Furthermore, despite the lower specific volume and denser crumb of barley breads with respect to wheat bread, no significant differences were seen in the degree of liking among the three breads after baking and during shelf-life, thus confirming the possibility for successful exploitation of barley flour in the baking industry.Bhatt and Gupta (2015), prepared healthy bread, enriched with protein and fiber, from composite flours formulations, to evaluate nutritional, phytochemical activity, functional and physiochemical properties of the flours and breads. Four different proportions of composite flours were used, i.e., 1) $50 \%$ refined wheat, $10 \%$ chickpea, $10 \%$ buckwheat, $10 \%$ sorghum, $10 \%$ sprouted barley and $10 \%$ sprouted wheat (MI), 2) $50 \%$ whole wheat, $10 \%$ chickpea, $10 \%$ buckwheat $10 \%$ sorghum, $10 \%$ sprouted barley and $10 \%$ sprouted wheat (MII), 3) 65\% refined wheat, 5\% chickpea, $5 \%$ buckwheat $5 \%$ sorghum, 5\% sprouted barley, $5 \%$ sprouted wheat, $5 \%$ corn flour and $5 \%$ defatted soy flour (RWI), 4) $65 \%$ whole wheat, $5 \%$ chickpea, 5\% buckwheat, 5\% sorghum, 5\% sprouted wheat, $5 \%$ sprouted barley, $5 \%$ corn flour and $5 \%$ defatted soy flour (RWII). They concluded that, the use of the formulated composite flour might be considered in the preparation of the bread. Lalit and Kochhar (2017), showed that, incorporation of barely flour at 25 percent level and germinated fenugreek seed powder at 5 percent level was highly acceptable. Supplemented bread showed increase in protein, fiber and reducing sugars. Value added bakery products were recommended for nutritional and health benefits because they were cost effective, nutritious and helps to manage different diseases.

Navickis (1987), prepared doughs from blends of a hard red spring wheat flour and drymilled corn products. The shear modulus, G, of these doughs increased with replacement of the wheat flour solids by corn products. Stress relaxation behavior at constant deformation was determined, from which a time for $50 \%$ relaxation was interpolated from probability plots of percent stress decay against log time. This relaxation time increased as more corn product was incorporated. Loaf volumes decreased as the relaxation time increased. Yaseen et al. (2007) evaluated the suitability of partially replacing wheat flour using triticale flour in Egyptian balady bread making. Wheat flour was partially replaced by triticale flour at ratios of 20,30, 40, and 50\%. They indicated that, triticale flour may be blended with wheat flour at levels as high as $50 \%$ without adversely affecting baking performance of balady bread. Hadnađev et al. (2011) showed that, Flours from different raw materials were tested in order to investigate their ability to mimic wheat flour dough behaviors during bread making and bread baking. Among tested alternative cereals (rice, corn), pseudo cereals (buckwheat, amaranth) and legumes (soybean); Rice and buckwheat flours expressed the most similar protein (water absorptions, stabilities and degrees of mechanical weakening) and starch (peak, minimum and setback torque) characteristics as wheat flour. Since Mixolab profile of wheat flour was located between rice and buckwheat flour profiles, it might be concluded that, blends of rice and buckwheat flours would give the optimal profile. Islam et al. (2011), reached that, bread volume decreased, whereas bread weight and moisture content increased with the increasing level of maize and brown rice flour. Rai et al. (2012), indicated that, the baking absorption was observed to increase with higher level of maize meal but it decreased when level of rice flour was increased. Loaf weight $(\mathrm{g})$ decreased with progressive increase in the proportion of maize meal but increased when rice flour incorporation was increased. Loaf volume, loaf height and specific volume decreased for progressively higher level of maize meal and rice flour. Begum et al. (2013), conducted a trial to develop composite bread with maize flour and also to evaluate the nutritional quality and sensory properties of resulting breads. They showed that, breads were produced from composite flour containing 10, 20, 25, 30 and $40 \%$ of maize flour and compared with wheat bread for various quality attributes of the 
developed products. Hussein et al. (2013), focused on substituting a part of wheat flour (WF) with whole meal barley (WBF), gelatinized corn flour (GCF) and both of them in balady bread. It is found that, WF supplemented with WBF: GCF (30:15\%) did not affected technological quality of balady bread and improved its nutritive values. Hussein et al. (2013), improved the nutritional, healthy values, and quality of balady bread by replacing wheat flour (WF) with gelatinized corn flour (GCF) and/ or whole meal barley (WBF), with the possibility of completing shortages of wheat raw material. They concluded that, wheat flour could be replaced with whole barely flour and gelatinized corn flour at the level of 30: $15 \%$ without drastic effect on properties of bread.

Harinder et al. (1999), showed that, pigeon pea flour was substituted at levels of $0,5,10,15$, $20,25 \%$ to wheat flour and whole wheat meal for bread and Chapatti making, respectively. The bread from $10 \%$ pigeon pea flour blend with $2-3 \%$ vital gluten and $0.5 \%$ SSL had high loaf volume and loaf quality. Blends containing $15 \%$ pigeon pea flour were acceptable for Chapatti .The increase in protein, iron and phosphorus content of the pigeon pea supplemented products could be utilized to improve the nutritional status of diets in school feeding programs and vulnerable sections of the population in developing nations where pigeon peas are available. Sharma et al. (1999), studied the effect of replacement of wheat flour with cowpea flour on rheological properties of dough and physical and sensory characteristics of some of the baked products .They indicated that, Loaf volume and overall acceptability scores of bread were reduced significantly beyond $150 \mathrm{~g} \mathrm{~kg} .1$ incorporation of cowpea flour.Abdel-Kader (2000), evaluated the physical, rheological, and baking properties of decorticated cracked broad beans-wheat composite flours and to determine the acceptability of the resulting bread. It was concluded that, the replacement of bread flour (WF) with up to $10 \%$ decorticated cracked broad beans flour produced acceptable Egyptian 'Balady' bread.Dhingra and Jood (2004), studied the effect of supplementation on baking characteristics of bread. they indicated that bread volume decreased with increasing amount of non-wheat flour substitution. They concluded that the substitution of wheat flour with soybean and barley flour up to an amount equivalent to $10 \%$ of full-fat and defatted soy flour, $15 \%$ for barley flour, full-fat soy + barley flour and defatted soy + barley flour produced acceptable bread loaves .Hooda and Jood (2005), developed wheat-fenugreek-based health bread; Used samples represented commonly grown varieties of wheat and fenugreek. They found that, additions of fenugreek (raw, soaked and germinated) up to the level of 15 per cent produced bread with a satisfactory loaf volume, whereas the 20 per cent level of sup- plementation caused a depression effect in loaf volume. Ribotta et al. (2005), examined the effect of several derivatives of soybean on dough properties and bread quality. They showed that, soy flours and soy protein isolates (SPIs) affected dough properties. Soy products were harmful to gluten formation, dough extensibility properties, gas retention properties and bread quality. Butt et al. (2011), made a study to investigate, partially replacing wheat flour with raw, germinated and fermented cowpea flour effects on baking and characteristics of bread .Raw, germinated and fermented cowpea flours were blended with wheat flour at 5, 10, 15 and $20 \%$ substitution level. The obtained results showed that The bread volume decreased with increasing the cowpea flour substitution, while, the loaf weight increased. Substitution of wheat flour with cowpea flour also affected the sensory characteristics of bread. Replacement of wheat flour with cowpea flour up to $10 \%$ of substitution level produced acceptable bread. Mohammed et al. (2012), evaluated the effect of chickpea addition at different concentration on wheat dough rheology and bread characteristics. They used partial substitution of wheat flour with chickpea flour at the levels of 10, 20 and $30 \%$. They showed that, chickpea addition with $<20 \%$ significantly impaired the volume, internal structure, and texture of the breads. Roberts et al. (2012), substituted Fenugreek gum (extruded and non-extruded) for wheat flour at $0 \%, 5 \%$ and $10 \%$ (w/w). They found that, the substitution of FG into bread dough at levels of $10 \%$ caused detrimental results to baked bread volume, texture and the general appearance. Ahmed (2014), determined the effect of the partial replacement of wheat flour by lupine flour. They reached that, concentration of lupine flour up to $10 \%$ can be used successfully in bakery products.Menon and Majumdar (2015), studied the composite flours prepared using refined wheat flour (WF), high protein soy flour (SF), sprouted mung bean flour (MF) and mango kernel flour (MKF). Three variations were formulated such as V-I (WF: SF: MF: MKF=85:5:5:5), V-II (WF: SF: MF: MKF=70:10:10:10), and V-III (WF: SF: MF: $M K F=60: 14: 13: 13)$. They found that, the Physical characteristics of the bread variations revealed a percentage decrease in loaf height (14 $\%)$ and volume (25\%) and $20 \%$ increase in loaf weight with increased substitution of composite flour. Lalit and Kochhar (2017), showed that, incorporation of barely flour at 25 percent level and germinated fenugreek seed powder at 5 percent level was highly acceptable.

The recent study was carried out with the objective of determining quality and sensory qualities of breads produced from variable substitutions of rice, sorghum, and naked barley flours along with local pulses flours. 


\section{MATERIALS AND METHODS}

The recent study included studying the possibility of substituting local cereals flours (rice, sorghum, and naked barley) to local bread wheat cultivars. Adding fenugreek local pulse flour and imported soybean flour to improve characters of bread was also included. Separate experiments were carried out for each bread wheat variety. The studied local bread wheat cultivars were Misr2,
Giza171 and Gemmiza11.Row materials for local cereals, fenugreek and bread wheat cultivars were obtained from Agricultural Research center, Ministry of Agriculture, Giza, Egypt.86\% extraction flour were prepared by following AACC;26-10 A method. Tempered cleaned grains milled by barabender quadrumat mill using the barabender procedure. For each local bread wheat cultivars, the following flour blends were prepared (Table1).

Table 1: list of studied flour blends that represent different levels of local cereals flour substitution and pulse flour addition

\begin{tabular}{|c|c|c|c|c|}
\hline \multirow{2}{*}{ Code } & \multirow{2}{*}{ Treatment } & \multicolumn{3}{|c|}{ Component of one kilogram blended flour } \\
\hline & & wheat & cereal & pulse \\
\hline 1 & WF $100 \%$ & 1000 & - & - \\
\hline 2 & $\mathrm{WF}+10 \% \mathrm{RF}$ & 900 & 100 & - \\
\hline 3 & $\mathrm{WF}+10 \% \mathrm{RF}+5 \% \mathrm{Fen}$ & 850 & 100 & 50 \\
\hline 4 & $\mathrm{WF}+10 \% \mathrm{RF}+5 \% \mathrm{So}$ & 850 & 100 & 50 \\
\hline 5 & $\mathrm{WF}+20 \% \mathrm{RF}$ & 800 & 200 & - \\
\hline 6 & $\mathrm{WF}+20 \% \mathrm{RF}+5 \% \mathrm{Fen}$ & 750 & 200 & 50 \\
\hline 7 & $\mathrm{WF}+20 \% \mathrm{RF}+5 \% \mathrm{So}$ & 750 & 200 & 50 \\
\hline 8 & $\mathrm{WF}+30 \% \mathrm{RF}$ & 700 & 300 & - \\
\hline 9 & $\mathrm{WF}+30 \% \mathrm{RF}+5 \% \mathrm{Fen}$ & 650 & 300 & 50 \\
\hline 10 & $\mathrm{WF}+30 \% \mathrm{RF}+5 \% \mathrm{So}$ & 650 & 300 & 50 \\
\hline 11 & $\mathrm{WF}+10 \% \mathrm{SF}$ & 900 & 100 & - \\
\hline 12 & $\mathrm{WF}+10 \% \mathrm{SF}+5 \% \mathrm{Fen}$ & 850 & 100 & 50 \\
\hline 13 & $\mathrm{WF}+10 \% \mathrm{Sf}+5 \%$ So & 850 & 100 & 50 \\
\hline 14 & $\mathrm{WF}+20 \% \mathrm{SF}$ & 800 & 200 & - \\
\hline 15 & $\mathrm{WF}+20 \% \mathrm{SF}+5 \% \mathrm{Fen}$ & 750 & 200 & 50 \\
\hline 16 & $\mathrm{WF}+20 \% \mathrm{SF}+5 \% \mathrm{So}$ & 750 & 200 & 50 \\
\hline 17 & $\mathrm{WF}+30 \% \mathrm{SF}$ & 700 & 300 & - \\
\hline 18 & $\mathrm{WF}+30 \% \mathrm{SF}+5 \% \mathrm{Fen}$ & 650 & 300 & 50 \\
\hline 19 & $\mathrm{WF}+30 \% \mathrm{SF}+5 \% \mathrm{So}$ & 650 & 300 & 50 \\
\hline 20 & $\mathrm{WF}+10 \% \mathrm{BF}$ & 900 & 100 & - \\
\hline 21 & $\mathrm{WF}+10 \% \mathrm{BF}+5 \% \mathrm{Fen}$ & 850 & 100 & 50 \\
\hline 22 & $\mathrm{WF}+10 \% \mathrm{BF}+5 \%$ So & 850 & 100 & 50 \\
\hline 23 & $\mathrm{WF}+20 \% \mathrm{BF}$ & 800 & 200 & - \\
\hline 24 & $\mathrm{WF}+20 \% \mathrm{BF}+5 \% \mathrm{Fen}$ & 750 & 200 & 50 \\
\hline 25 & $\mathrm{WF}+20 \% \mathrm{BF}+5 \%$ So & 750 & 200 & 50 \\
\hline 26 & $\mathrm{WF}+30 \% \mathrm{BF}$ & 700 & 300 & - \\
\hline 27 & $\mathrm{WF}+30 \% \mathrm{BF}+5 \% \mathrm{Fen}$ & 650 & 300 & 50 \\
\hline 28 & $\mathrm{WF}+30 \% \mathrm{BF}+5 \% \mathrm{So}$ & 650 & 300 & 50 \\
\hline 29 & $\mathrm{WF}+5 \% \mathrm{Fen}$ & 950 & - & 50 \\
\hline 30 & $\mathrm{WF}+5 \%$ So & 950 & - & 50 \\
\hline 31 & $\mathrm{WF}+5 \% \mathrm{Fen}+5 \%$ So & 900 & - & 100 \\
\hline
\end{tabular}

WF; Wheat flour

BF; Barley flour
RF; Rice flour

Fen; Fenugreek flour
SF; Sorghum flour SO; Soybean flour 
For each studied flour blend of each bread wheat cultivar, the following procedure was followed during dough preparation; doughs comprising flour (200g) compressed yeast $(2 \mathrm{~g})$, salt $(3 \mathrm{~g})$ and various(amounts of water were mixed using) Barabender, after mixing doughs were placed in sealed plastic containers and allowed to ferment at $30^{\circ} \mathrm{C}$ for one $\mathrm{h}$. After the bulk key, packed under vacuum $(450 \mathrm{~g}$ per pack), as welfermentation, doughs were degassed by hand pressure las fresh compressed yeast, produced locally by and scaled off into three pieces of $100 \mathrm{gm}$. The dough Sugar and Integrated Industries Company and pieces were rolled by hand into balls, placed on a Starch and Yeast Company was used for Balady wood board previously dusted with flour, and covered Bread production.

with aplastic sheet to avoid surface drying and subsequent skin formation, these were left for $10 \mathrm{~min}$ at $28 \pm 2^{\circ} \mathrm{C}$ for intermediate proofing .The dough pieces

\section{RESULTS AND DISCUSSION}

Measured bread characters included loaf diamewere then hand. Rolled to $10 \mathrm{~mm}$ thickness using a ter before and after baking and loaf weight after bakspacing guide, after which they were passed twice ing. Table 2 showed the analysis of variance for bread through a pair of steel rollers. The sheeted doughs characters as affected by wheat cultivars, flour blends were placed on wood boards lightly dusted with flour and their interaction. Wheat cultivars were significantfor final proofing at $28 \pm 2^{\circ} \mathrm{C} 65 \pm 5 \% \mathrm{r}$.h. for $30 \mathrm{~min}$. ly similar in all measured bread characters. MeanOven temperature was set at $400^{\circ} \mathrm{C}$ and baking was while, flour blends significantly $(\mathrm{p} \geq 0.01)$ affected all carried out for $90 \mathrm{sec}$. on a preheated aluminum tray. bread characters. Also, the interactions between wheat This combination of temperature and time is the most cultivar and flour blend were significant $(\mathrm{p} \geq 0.01)$ in all widely used in commercial practice and thus was se- measured bread characters.

lected for this technique. After baking the loaves were

Table 2: Mean squares of bread characters represented by loaf diameter before and after baking and loaf weight after baking as affected by wheat cultivar and cereal and/ or pulse flour supplementation

\begin{tabular}{|l|l|c|c|c|}
\hline \multirow{2}{*}{ Source of variation } & \multirow{2}{*}{ d.f. } & $\begin{array}{c}\text { Loaf diameter } \\
\text { before baking }\end{array}$ & $\begin{array}{c}\text { Loaf diameter } \\
\text { after baking }\end{array}$ & $\begin{array}{c}\text { Loaf weight after } \\
\text { baking }\end{array}$ \\
\cline { 3 - 5 } & & $7.683^{\text {n.s }}$ & $6.852^{\text {n.s }}$ & $376.6^{\text {n.s }}$ \\
Cultivar (c) & 2 & 4.140 & 3.488 & 2.379 \\
Error & 4 & $8.701^{* *}$ & $8.545^{* *}$ & $128.0^{* * *}$ \\
\hline Flour blends (B) & 30 & $3.896^{* *}$ & $3.688^{* *}$ & $38.64^{* *}$ \\
C $\times$ B & 60 & 1.363 & 1.306 & 7.221 \\
Error & 180 & & & \\
\hline
\end{tabular}

${ }^{\text {n.s }}$; not significantly different.

**; indicate significance at 0.01 level.

\section{Loaf diameter before baking:}

Loaf diameter before baking of wheat flour blends with rice and pulses flours were presented in Table 3. Loaf diameter before baking indicated the ability of fermented dough to spread in form of loaf. In the meantime, it reflects the resistance of dough to spread (shrank) during loaf formation. Rice flour blending to wheat flour at $10 \%$ level, significantly gave broader loaf diameter (20.67 vs. $21.04 \mathrm{~cm}$ for wheat flour and wheat flour $+10 \%$ rice flour, respectively). While, additional substitution of wheat flour by $5 \%$ fenugreek flour increased the strength of blend dough reflected in significantly narrower loaf diameter $(19.94 \mathrm{~cm})$. Substitution of wheat flour by $5 \%$ soybean flour and $10 \%$ rice flour expressed significantly similar dough strength to those of either $100 \%$ wheat flour or blend of $10 \%$ rice flour $+5 \%$ fenugreek flour + $85 \%$ wheat flour $(20.02 \mathrm{~cm})$.
Raising the level of rice flour substitution to $20 \%$ gave lower loaf diameter relative to $10 \%$ rice flour level (20.22 vs. $21.04 \mathrm{~cm}$ for 20 and $10 \%$ rice flour substitution levels, respectively). This might indicate an increase in dough elasticity (loaf shrunk). Also, the addition of 5\% fenugreek flour to blend of $20 \%$ rice flour, gave substantial reduction in loaf diameter $(19.78 \mathrm{~cm})$. While, the least significant loaf diameter was expressed by the blend of $20 \%$ rice flour $+5 \%$ soybean flour $+75 \%$ wheat flour $(18.63 \mathrm{~cm})$.

As for $30 \%$ substitution level with rice flour, all blends whether with or without pulse flours substitution gave similar loaf diameter. This might due to the effect of starch granules in dough characters that entailed lower elasticity $(20.15,20.67$ and $20.15 \mathrm{~cm}$ for blends of wheat flour, $30 \%$ rice flour, same blend $+5 \%$ fenugreek flour and $5 \%$ soybean flour, respectively). 
Regarding the interaction between wheat cultivars and rice flour blends, Gimmeza11 wheat flour blends, significantly enjoyed lower loaf diameter, irrespective of the studied components of the flour blend. Also, the least significant loaf diameter was expressed by Gimmeza11 wheat flour blend with $20 \%$ rice flour $+5 \%$ soybean flour $(17.35 \mathrm{~cm})$.

Table 3: Effect of rice flour and pulses Flour substitution on loaf diameter $(\mathrm{cm})$ before baking of flour blends

\begin{tabular}{|l|c|c|c|c|}
\hline \multirow{2}{*}{\multicolumn{2}{|c|}{ Flour blends }} & \multicolumn{4}{c|}{ Wheat cultivar } \\
\cline { 2 - 5 } & Misr2 & Giza171 & Gimmeza11 & Combined \\
\hline WF 100\% & 21.030 & 21.063 & 19.910 & 20.668 \\
\hline WF+ 10\% RF & 20.743 & 21.220 & 21.170 & 21.044 \\
\hline WF+10\% RF+ 5\% Fen & 20.547 & 20.590 & 18.687 & 19.941 \\
\hline WF+10\% RF+ 5\% Soy & 21.060 & 19.960 & 19.050 & 20.023 \\
\hline WF+ 20\% RF & 20.983 & 20.863 & 18.827 & 20.224 \\
\hline WF+ 20\% RF+ 5\% Fen & 19.677 & 19.987 & 19.690 & 19.784 \\
\hline WF+ 20\% RF+ 5\% Soy & 18.750 & 19.797 & 17.353 & 18.633 \\
\hline WF+ 30\% RF & 21.330 & 19.180 & 19.933 & 20.148 \\
\hline WF+ 30\% RF+ 5\% Fen & 21.043 & 19.217 & 21.740 & 20.667 \\
\hline WF+ 30\% RF+ 5\% Soy & 20.963 & 19.153 & 20.320 & 20.146 \\
\hline
\end{tabular}

WF; Wheat Flour RF; Rice Flour Fen; Fenugreek Flour Soy; Soybean flour

Tanaka (1972), studied the influenced of rice flour substitute on the baking quality of wheat flour and the method to improve the rice bread quality were examined. The results were as follows; (1) the baking quality of wheat flour and also the loaf volume are reduced by substituting rice flour to which the use of surfactant is effective, (2) extension of the final proofing time and the use of $\alpha$-amylase are effective to increase the loaf volume and (3) it was better not to reduce too much the size of rice flour particle. Hadnađev et al. (2011) showed that, Flours from different raw materials were tested in order to investigate their ability to mimic wheat flour dough behavior during bread making and bread baking. Among tested alternative cereals (rice, corn), pseudo cereals (buckwheat, amaranth) and legumes (soybean). Rice and buckwheat flours expressed the most similar protein (water absorptions, stabilities and degrees of mechanical weakening) and starch (peak, minimum and setback torque) characteristics as wheat flour .Islam et al. (2011), reached that, bread volume decreased, whereas bread weight and moisture content increased with the increasing level of maize and brown rice flour. Also, Bread quality in respects of bread volume and crumb texture were improved by using $2.5 \%$ yeast, $5 \%$ sugar, $5 \%$ fat and $0.6 \%$ improver. Rai et al. (2012), determined proximate composition and pasting properties of raw materials, bread making quality and sensory qualities of breads produced from varying substitutions of rice flour and maize meal with wheat flour. They indicated that, the baking absorption was observed to increase with higher level of maize meal, but it decreased when level of rice flour was increased. Loaf weight (g) decreased with progressive increase in the proportion of maize meal but increased when rice flour incorporation was increased. Loaf volume, loaf height and specific volume decreased for progressively higher level of maize meal and rice flour. The sensory evaluation revealed that $25 \%$ replacement of wheat flour was found to be more acceptable than control sample. Khoshgozaran-Abras et al. (2014), indicated that, it was feasible to incorporate brown rice (BR) flour for baking Barbary flat bread. However, the threshold of BR flour addition should be $\leq 5 \%$. This is simply because, dough made from blend flour fortified with $5 \%$ BR flour, due to rheological evaluation, was strong and baked flat bread was highly ranked acceptable by panelists and remained fresher in comparison with other treatments by the end of storage.

Effect of sorghum flour and pulses flour substitution on loaf diameter before baking of wheat cultivars flour blends were presented in Table 4. Sorghum flour substitution at $10 \%$ level of wheat flour whether alone or with additional $5 \%$ substitution by any of fenugreek or soybean flours had not significantly affected dough elasticity which altered loaf diameter (as 20.67, 20.25, 20.00 and $19.82 \mathrm{~cm}$ for wheat flour, wheat flour $+10 \%$ sorghum flour, wheat flour $+10 \%$ sorghum flour $+5 \%$ fenugreek flour and wheat flour $+10 \%$ sorghum flour $+5 \%$ soybean flour, respectively). Although, the blends gave significantly similar loaf diameter, their seems a tendency for higher dough elasticity, since, loaf diameter was shrinking.

Substitution of wheat flour by sorghum flour at $20 \%$ level significantly increased dough elasticity (reduced loaf diameter) relative to $100 \%$ wheat flour 
$(18.23 \mathrm{~cm})$. Significantly higher dough elasticity (lower loaf diameter) was recorded when $20 \%$ sorghum flour substitution to wheat flour was coupled with $5 \%$ substitution of soybean flour $(17.89 \mathrm{~cm})$. Addition of $5 \%$ fenugreek flour to $20 \%$ sorghum flour as a substitute to wheat flour gave significantly similar loaf diameter to $20 \%$ sorghum flour substitution to wheat flour $(18.38 \mathrm{~cm})$.

Increasing the level of sorghum flour substitution to wheat flour in the blend to $30 \%$ gave lower dough elasticity (larger loaf diameter) relative to $20 \%$ level of substitution. In the meantime, figures of loaf diameter for $30 \%$ sorghum flour blends were significantly similar to full wheat flour and blends with $10 \%$ sorghum flour substitution.

As for the interaction between wheat cultivar and flour blends, the highest dough elasticity (lowest loaf diameter) was presented by Misr2 cultivar blend with $20 \%$ sorghum flour $+5 \%$ soybean flour $(16.21 \mathrm{~cm})$

Table 4: Effect of sorghum flour and pulses Flour substitution on loaf diameter before baking of flour blends of wheat cultivars

\begin{tabular}{|l|l|l|l|l|}
\hline \multirow{2}{*}{ Flour blends } & \multicolumn{4}{c|}{ Wheat cultivar } \\
\cline { 2 - 5 } & \multicolumn{1}{|c|}{ Misr2 } & \multicolumn{1}{c|}{ Giza171 } & Gimmeza11 & \multicolumn{1}{c|}{ Combined } \\
\hline WF 100\% & 21.030 & 21.063 & 19.910 & 20.668 \\
\hline WF+ 10\% SF & 21.253 & 19.230 & 20.267 & 20.250 \\
\hline WF+10\% SF+ 5\% Fen & 20.787 & 19.417 & 19.810 & 20.004 \\
\hline WF+10\% SF+ 5\% Soy & 21.193 & 18.307 & 19.970 & 19.823 \\
\hline WF+ 20\% SF & 17.957 & 17.773 & 18.973 & 18.234 \\
\hline WF+ 20\% SF+ 5\% Fen & 18.287 & 16.900 & 19.967 & 18.384 \\
\hline WF+ 20\% SF+ 5\% Soy & 16.213 & 17.547 & 19.913 & 17.891 \\
\hline WF+ 30\% SF & 20.900 & 19.973 & 20.167 & 20.347 \\
\hline WF+ 30\% SF+ 5\% Fen & 20.877 & 18.747 & 20.580 & 20.068 \\
\hline WF+ 30\% SF+ 5\% Soy & 20.900 & 19.163 & 21.917 & 20.660 \\
\hline
\end{tabular}

\section{WF; Wheat Flour SF; Sorghum Flour}

Loaf diameter as an indicator of dough elasticity as affected by barley flour and pulse flour substitution was presented in Table 56. loaf diameter was significantly reduced when barley flour was blended to wheat flour at $10 \%$ level (high dough elasticity) (19.09 vs. 20.67 for wheat flour $+10 \%$ barley flour blend and full wheat flour, respectively). Additional substitution to wheat flour by $5 \%$ fenugreek flour reduced dough elasticity (larger loaf diameter) (20.44 $\mathrm{cm})$. Meanwhile, 5\% soybean flour substitution in wheat $+10 \%$ barley flour gave lower loaf diameter (higher elasticity) $(19.30 \mathrm{~cm})$.

Barley flour substitution to wheat flour at $20 \%$ level gave lower loaf diameter $(19.60 \mathrm{~cm})$. Additional substitution of wheat flour by $5 \%$ fenugreek flour or 5\% soybean flour, significantly improved dough elasticity (reduced loaf diameter) (17.29 and $17.64 \mathrm{~cm}$ for the former and latter blends, respectively).

Substitution by barley flour at $30 \%$ level whether alone or with additional substitution of $5 \%$ fenugreek or soybean flours gave significantly similar loaf diameter $(20.03,20.85$ and $19.71 \mathrm{~cm}$ for wheat flour substituted by $30 \%$ barley flour, wheat flour substituted by $30 \%$ barley flour and $5 \%$ fenugreek flour and wheat flour substituted by $30 \%$ barley flour and 5\% soybean flour blends, respectively).

The simple effect wheat cultivar $\times$ flour blend interaction expressed the least significant loaf di-
Fen; Fenugreek Flour Soy; Soybean flour

ameter (highest dough elasticity) by Misr2 wheat flour blend with $20 \%$ barley flour and of $5 \%$ fenugreek flour or 5\% soybean flour (15.71 and 16.23 $\mathrm{cm}$ for the former and the latter, respectively).

Orthogonal comparisons between blends of wheat flour with $20 \%$ vs. $30 \%$ rice flour substitution (Table 6) showed that, blends of Misr2 showed significantly $(p \geq 0.003)$ higher loaf diameter $(0.654 \mathrm{~cm})$, while, that difference in case of Giza171 cultivar blends was insignificant. Gimmeza11 blends showed significantly higher loaf diameter $(1.021 \mathrm{~cm})$ with increasing rice flour substitution level to $30 \%$.

Orthogonal comparisons between different levels of sorghum flour substitution to wheat flour reflected on loaf diameter before baking were presented in Table 7. Wheat flour blends that contained $10 \%$ sorghum flour vs. $20 \%$ sorghum flour showed a reduction in loaf diameter reached 1.796 $(\mathrm{p} \geq 0.001), 0.789 \quad(\mathrm{p} \geq 0.007)$ and $0.199(\mathrm{p} \geq 0.381)$ $\mathrm{cm}$ for Misr2, Giza171 and Gimmeza11 wheat cultivars, respectively). Whereas, comparison between $20 \%$ vs. $30 \%$ sorghum flour substitution over pulses flours, showed an increase in loaf diameter of Misr2 blends $(-1.703 \mathrm{~cm} \mathrm{p} \geq 0.001)$, Giza171 blends $(-0.944 \mathrm{~cm} \mathrm{p} \geq 0.001)$ and Gimmeza11 (-0.635 $\mathrm{p} \geq 0.05)$. This might indicate a loss of dough elasticity when sorghum flour substitution level surpasses $20 \%$ of the blend. 
Table 5: Effect of barley flour and pulses Flour substitution on loaf diameter before baking of flour blends of wheat cultivars

\begin{tabular}{|l|l|l|l|l|}
\hline \multirow{2}{*}{ Flour blends } & \multicolumn{4}{c|}{ Wheat cultivar } \\
\cline { 2 - 5 } & \multicolumn{1}{|c|}{ Misr2 } & \multicolumn{1}{c|}{ Giza171 } & \multicolumn{1}{c|}{ Gimmeza11 } & \multicolumn{1}{c|}{ Combined } \\
\hline WF 100 \% & 21.030 & 21.063 & 19.910 & 20.668 \\
\hline WF+ 10\% BF & 20.713 & 18.000 & 18.580 & 19.098 \\
\hline WF+10\% BF+ 5\% Fen & 21.747 & 20.570 & 19.017 & 20.444 \\
\hline WF+10\% BF+ 5\% Soy & 20.610 & 18.520 & 18.757 & 19.296 \\
\hline WF+ 20\% BF & 18.513 & 19.090 & 21.193 & 19.599 \\
\hline WF+ 20\% BF+ 5\% Fen & 15.710 & 17.887 & 18.273 & 17.290 \\
\hline WF+ 20\% BF+ 5\% Soy & 16.230 & 17.607 & 19.080 & 17.639 \\
\hline WF+ 30\% BF & 20.953 & 19.943 & 19.193 & 20.030 \\
\hline WF+ 30\% BF+ 5\% Fen & 20.403 & 21.583 & 20.567 & 20.851 \\
\hline WF+ 30\% BF+ 5\% Soy & 20.010 & 19.957 & 19.153 & 19.707 \\
\hline
\end{tabular}
WF; Wheat Flour
BF; Barley Flour
Fen; Fenugreek Flour
Soy; Soybean flour

Table 6: Orthogonal comparisons between different levels of rice flour substitution to wheat flour reflected on loaf diameter before baking of the flour blend

\begin{tabular}{|c|c|c|c|c|c|c|}
\hline \multirow{3}{*}{ Comparisons } & \multicolumn{6}{|c|}{ Wheat cultivar } \\
\hline & \multicolumn{2}{|r|}{ Misr2 } & \multicolumn{2}{|c|}{ Giza171 } & \multicolumn{2}{|c|}{ Gimmeza11 } \\
\hline & Effect & Significance & Effect & Significance & Effect & Significance \\
\hline $\begin{array}{l}\mathrm{WF}+10 \% \mathrm{RF} v s . \\
\mathrm{WF}+20 \% \mathrm{RF}\end{array}$ & -0.490 & 0.022 & -0.187 & 0.437 & -0.506 & 0.122 \\
\hline $\begin{array}{l}\mathrm{WF}+20 \% \mathrm{RF} v s . \\
\mathrm{WF}+30 \% \mathrm{RF}\end{array}$ & 0.654 & 0.003 & -0.516 & 0.073 & 1.021 & 0.002 \\
\hline
\end{tabular}

WF; Wheat Flour

RF; Rice Flour

Fen; Fenugreek Flour

Soy; Soybean flour

Table7: Orthogonal comparisons between different levels of sorghum flour substitution to wheat flour reflected on loaf diameter before baking of the flour blend

\begin{tabular}{|l|l|l|l|l|l|l|}
\hline \multirow{2}{*}{ Comparisons } & \multicolumn{3}{|c|}{ Wheat cultivar } \\
\cline { 2 - 7 } & \multicolumn{3}{|c|}{ Misr2 } & \multicolumn{2}{c|}{ Giza171 } & \multicolumn{3}{c|}{ Gimmeza11 } \\
\cline { 2 - 7 } & Effect & Significance & Effect & Significance & Effect & Significance \\
\hline $\begin{array}{l}\text { WF+ 10\% SF } v \cdot s \\
\text { WF+20\% SF }\end{array}$ & -1.796 & 0.000 & -0.789 & 0.007 & -0.199 & 0.381 \\
\hline $\begin{array}{l}\text { WF+ 20\%SF v.s } \\
\text { WF+30\%SF }\end{array}$ & 1.703 & 0.000 & 0.944 & 0.001 & 0.635 & 0.053 \\
\hline
\end{tabular}

WF; Wheat Flour SF; Sorghum Flour

Orthogonal comparisons between different levels of barley flour substitution to wheat flour reflected on loaf diameter before baking were presented in Table 8. Comparison between blends with $10 \%$ vs. $20 \%$ barley flour showed reduction in loaf diameter reached $2.103(\mathrm{p} \geq 0.001)$ for Misr2 blends, $0.418 \mathrm{~cm}(\mathrm{p} \geq 0.145)$ for Giza171, whereas, loaf diameter increased by $0.366(p \geq 0.26)$ in Gimmeza11 wheat blends. Comparison between $20 \%$ vs. $30 \%$ barley flour substitution levels, showed an increase in loaf diameter with increasing substitution level reached $1.819(\mathrm{p} \geq 0.001)$ for Misr2, $1.150 \mathrm{~cm}(\mathrm{p} \geq 0.001)$ for Giza171 and 0.061 $\mathrm{cm}(\mathrm{p} \geq 0.03)$ for Gimmezal 1 .
Fen; Fenugreek Flour Soy; Soybean flour

Comparisons between different cereal substitution to wheat flour (Table 9), showed that rice flour vs. sorghum flour in wheat flour blends showed that, rice flour blends had higher loaf diameter by $0.374 \mathrm{~cm}(\mathrm{p} \geq 0.003)$ for Misr2, $0.717 \mathrm{~cm}$ ( $p \geq 0.001$ ) for Giza171, whereas, blends with Gimmeza11 wheat cultivar respond differently. The difference between blends with rice flour $v s$. blends with barley flour, showed larger loaf diameter for blends with rice flour reached $0.567(\mathrm{p} \geq 0.001), \quad 0.378 \quad(\mathrm{p} \geq 0.02) \quad$ and 0.164 $(\mathrm{p} \geq 0.78)$ for Misr2, Giza171 and Gimmeza11 wheat cultivars respectively. 
Table 8: Orthogonal comparisons between different levels of barley flour substitution to wheat flour reflected on loaf diameter before baking of the flour blend

\begin{tabular}{|l|l|l|l|l|l|l|}
\hline \multirow{2}{*}{ Comparisons } & \multicolumn{6}{c|}{ Wheat cultivar } \\
\cline { 2 - 7 } & \multicolumn{2}{|c|}{ Misr2 } & \multicolumn{2}{c|}{ Giza171 } & \multicolumn{2}{c|}{ Gimmeza11 } \\
\cline { 2 - 7 } & \multicolumn{1}{|c|}{ Effect } & Signifi- & \multicolumn{1}{|c|}{ Effect } & \multicolumn{1}{c|}{ Signifi- } & Effect & Signifi- \\
\hline $\begin{array}{l}\text { WF+ 10\% BF v.s } \\
\text { WF+20\% BF }\end{array}$ & -2.103 & 0.000 & -0.418 & 0.145 & 0.366 & 0.261 \\
\hline $\begin{array}{l}\text { WF+ 20\%BF v.s } \\
\text { WF+30\%BF }\end{array}$ & 1.819 & 0.000 & 1.150 & 0.000 & 0.061 & 0.036 \\
\hline
\end{tabular}

WF; Wheat Flour BF; Barley Flour Fen; Fenugreek Flour Soy; Soybean flour

Table 9: Orthogonal comparison for the effect of pulse flours supplementation to wheat /local cereals flours on loaf diameter before baking of cereal flour blend

\begin{tabular}{|l|l|l|l|l|l|l|}
\hline \multirow{2}{*}{ Comparisons } & \multicolumn{5}{|c|}{ Wheat cultivar } \\
\cline { 2 - 7 } & \multicolumn{2}{|c|}{ Misr2 } & \multicolumn{2}{c|}{ Giza171 } & \multicolumn{2}{c|}{ Gimmeza11 } \\
\cline { 2 - 7 } & Effect & Significance & Effect & Significance & Effect & Significance \\
\hline $\begin{array}{l}\text { WF+ RF } v . s \\
\text { WF+SF }\end{array}$ & -0.374 & 0.003 & -0.717 & 0.000 & 0.266 & 0.158 \\
\hline $\begin{array}{l}\text { WF+RF } v . s \\
\text { WF+BF }\end{array}$ & -0.567 & 0.000 & -0.378 & 0.024 & -0.164 & 0.779 \\
\hline
\end{tabular}

Orthogonal comparisons for the effect of pulse flour supplementation to wheat/local cereals flours on loaf diameter before baking for flour blends were presented in Table 10. Fenugreek flour $v$ s. soybean flour in blends gave larger $(0.208$ $\mathrm{cm}(\mathrm{p} \geq 0.07), 0.198 \mathrm{~cm}(\mathrm{p} \geq 0.21)$ and $0.002 \mathrm{~cm}$ $(\mathrm{p} \geq 0.001)$ for Misr2, Giza171 and Gimmeza11 cultivars, respectively) loaf diameter. Whereas, blends that included both of fenugreek and soybean flour $v s$. those with fenugreek flour had less loaf diameter by $0.102 \mathrm{~cm}(\mathrm{p} \geq 0.039)$ and $0.253 \mathrm{~cm}$ $(\mathrm{p} \geq 0.001)$ for Misr2 and Giza171 cultivars. Whereas, Gimmeza11 blends showed inverse response $(-0.093 \mathrm{~cm}(\mathrm{p} \geq 0.219)$.

In the meantime, comparison between blends included fenugreek + soybean flours $v s$. those with soybean flour showed a superiority of the latter of loaf diameter reached $0.140 \mathrm{~cm}(\mathrm{p} \geq 0.005)$ in Misr2 blends and $0.289 \mathrm{~cm}(\mathrm{p} \geq 0.0011)$ in Giza171 blends. While Gimmeza11 showed inverse response with superiority in loaf diameter of blends contained the two pulse flours.

Table10: Orthogonal comparison for the effect of pulse flour supplementation to wheat local cereals flours on loaf diameter before baking of flour blend

\begin{tabular}{|l|c|c|c|c|c|c|}
\hline \multirow{2}{*}{\multicolumn{1}{|c}{ Comparisons }} & \multicolumn{7}{c|}{ Wheat cultivar } \\
\cline { 2 - 7 } & \multicolumn{2}{|c|}{ Misr2 } & \multicolumn{2}{c|}{ Giza171 } & \multicolumn{2}{c|}{ Gimmeza11 } \\
\cline { 2 - 7 } & Effect & Signifi- & Effect & Signifi- & Effect & Signifi- \\
\hline $\begin{array}{l}\text { WF + (RF,SF,BF)+Fen. vs. } \\
\text { WF + (RF, SF, BF) + SO }\end{array}$ & -0.208 & 0.072 & -0.198 & 0.208 & -0.002 & 0.000 \\
\hline $\begin{array}{l}\text { WF + Fen +SO vs. } \\
\text { WF + Fen }\end{array}$ & 0.102 & 0.039 & 0.253 & 0.000 & -0.093 & 0.219 \\
\hline $\begin{array}{l}\text { WF + Fen.+ SO vs. } \\
\text { WF + SO }\end{array}$ & 0.140 & 0.005 & 0.289 & 0.000 & -0.093 & 0.221 \\
\hline
\end{tabular}

\section{Loaf diameter after baking:}

Table 11 illustrated loaf diameter measures after baking which stand for uniformity of loaf appearance affected by change in mass of constitutes correlated with loss of moisture and maturation data reflecting the effect of rice and pulse flours substitution. Although there were fluctuations on scored measures with variable blends, differences due to 10,20 or $30 \%$ rice flour substitution with or without fenugreek or soybean flour had not reached the level of significance, the least significant loaf diameter after baking resulted when Misr2 wheat flour was substituted with $20 \%$ rice flour $+5 \%$ soybean flour $(17.74 \mathrm{~cm})$. This val- ue was insignificantly different from those scored for Gimmeza11 wheat flour substituted with $10 \%$ rice flour $+5 \%$ fenugreek or soybean flours (17.62 and $17.97 \mathrm{~cm}$ for blend with fenugreek or soybean flours, respectively). It was valuable to notice that loaves made from full wheat flour, expressed values of loaf diameter after baking of larger magnitude than those expressed by flour blends that contained 10 or $20 \%$ rice flour.

Effect of sorghum flour substitution to wheat flour on loaf diameter after baking were presented in Table 12. It was obvious that, loaf diameter after baking was negatively affected by rice flour substitution at level or $10 \%$ plus $5 \%$ fenugreek or soy- 
bean flours. That negative effect had not reached the level of significance $(19.67,19.26,18.96$ and 18.81 full wheat, substitution by $10 \%$ rice flour, substitution by $10 \%$ rice flour $+5 \%$ fenugreek flour and substitution by $10 \%$ rice flour $+5 \%$ soybean flour, respectively). Raising the level of sorghum flour substitution to $20 \%$, gave the least significant figures for the loaf diameter after baking (17.46, 17.40 and $16.89 \mathrm{~cm}$ for blends of wheat flour $+20 \%$ sorghum flour, wheat flour, wheat flour $+20 \%$ sorghum flour $+5 \%$ fenugreek flour

Table 11: Effect of rice flour and pulses Flour substitution on loaf diameter after baking of flour blends of wheat cultivars

\begin{tabular}{|l|c|c|c|c|}
\hline \multirow{2}{*}{ Flour blends } & \multicolumn{4}{c|}{ Wheat cultivar } \\
\cline { 2 - 5 } & Misr2 & Giza171 & Gimmeza11 & Combined \\
\hline WF 100\% & 20.02 & 20.06 & 18.94 & 19.67 \\
\hline WF+ 10\% RF & 19.76 & 20.23 & 20.18 & 20.06 \\
\hline WF+10\% RF+ 5\% Fen & 19.54 & 19.56 & 17.62 & 18.90 \\
\hline WF+10\% RF+ 5\% Soy & 20.05 & 19.00 & 17.97 & 19.01 \\
\hline WF+ 20\% RF & 19.87 & 19.86 & 17.85 & 19.19 \\
\hline WF+ 20\% RF+ 5\% Fen & 18.56 & 19.11 & 18.76 & 18.81 \\
\hline WF+ 20\% RF+ 5\% Soy & 17.74 & 18.80 & 18.00 & 18.18 \\
\hline WF+ 30\% RF & 20.33 & 18.16 & 18.95 & 19.14 \\
\hline WF+ 30\% RF+ 5\% Fen & 20.07 & 18.23 & 20.61 & 19.64 \\
\hline WF+ 30\% RF+ 5\% Soy & 20.06 & 18.04 & 19.30 & 19.14 \\
\hline
\end{tabular}

WF; Wheat Flour RF; Rice Flour Fen; Fenugreek Flour Soy; Soybean flour

Bhatt and Gupta (2015), prepared healthy bread, enriched with protein and fiber, from composite flours formulations, to evaluate nutritional, phytochemical activity, functional and physiochemical properties of the flours and breads. Composites flour prepared using whole grain flours of sorghum, chickpea, and buckwheat, sprouted barley and sprouted wheat blended with refined wheat flour and whole wheat flour, not only increased the nutritive value but also, the phytochemical characteristic of the bread. From the study, data revealed that, nutritionally and organoleptically accepted bread (BII) after baking showed high flavonoid content. The composite bread (B-II) also consisted high amount of fiber content which make it functional product good for diabetic people. The baking loss was found to be in the acceptable range.Sibanda et al. (2015) studied the effect of partial substitution of wheat flour with white grain sorghum flour on the rheological properties and bread making quality of the composites. Composite flours containing 10\%, 20\% and 30\% sorghum were analyzed for their physicochemical composition. Sorghum addition resulted in a decrease in bread volume with sorghum replacement of higher than $20 \%$. The incorporation of sorghum at $10 \%$ produces bread of similar quality to wheat flour. and wheat flour $+20 \%$ sorghum flour $+5 \%$ soybean flour, respectively). Additional substitution by a higher level of sorghum flour reached $30 \%$ wether alone or with $5 \%$ pulses flour-maintained loaf diameter after baking to a level similar to that of full wheat flour. The least loaf diameter after baking was that expressed by blend of Misr2 wheat flour $+20 \%$ sorghum flour $+5 \%$ soybean flour $(15.28 \mathrm{~cm})$.

Vásquez et al. (2016), partially substituted wheat flour with sorghum (SF), oat (OF), or corn (CF) flours at the 2.5, 5, 7.5, and 10\% levels. They found that low substitutions could considerably reduce the cost of raw materials and could nutritionally improve products with cereal blends. However, they added that it is necessary to evaluate any changes in bread characteristics.

Barley flour and pulses flour substitution effects on loaf diameter after baking were presented in Table 12. Substitution of wheat flour by $10 \%$ barley flour blend gave significantly lower loaf diameter (19.67 vs. $18.17 \mathrm{~cm}$ for full wheat flour and wheat flour $+10 \%$ barley flour, respectively). That effect was true in Giza171 and Gimmeza11 wheat cultivars flour $(17.21$ and $17.71 \mathrm{~cm}$ for the former and the latter, respectively). Also, paradoxically to the other studied wheat cultivars, the blend of Gimmeza11 wheat flour $+10 \%$ barley flour $+5 \%$ fenugreek flour showed significantly lower loaf diameter after baking $(18.01 \mathrm{~cm})$. Raising the level of barley flour substitution to $20 \%$ of Misr2 and Giza171 wheat flour cultivars, resulted in significantly lower loaf diameter after baking (17.53and $18.00 \mathrm{~cm}$ for Misr2 and Giza171 wheat cultivars, respectively). Meanwhile, Gimmeza11 wheat flour blend with $20 \%$ barley flour main- 
tained higher loaf diameter $(20.14 \mathrm{~cm})$. Addition substitution by $5 \%$ fenugreek or $5 \%$ soybean flour to wheat $20 \%$ barley flours blends, resulted in significantly lower loaf diameter after baking (16.22 and $16.55 \mathrm{~cm}$ for blend of $20 \%$ barley flour $+5 \%$ fenugreek flour and $20 \%$ barley flour $+5 \%$ soybean flour, respectively). The least loaf diameter after baking were expressed by Misr2 wheat flour substituted by $20 \%$ barley flour and $5 \%$ fenugreek or $5 \%$ soybean flours $(14.55$ and $15.18 \mathrm{~cm}$ for the former and the latter, respectively). Blends of wheat flour substituted by $30 \%$ barley flour maintained similar loaf diameter after baking to that of full any of the studied wheat cultivars flour.

Niffenegger (1964) showed that, the starch and proteins of barley and wheat flour behave differently. The starch of barley flour has less thickening capacity and less water absorption than wheat. The protein has less gluten-like strength. Baked products which are dependent on glutenlike strength are made less successfully from barley flour than from wheat flour. Appearance and flavor are usually affected by the addition of barley flour. Sollars and Rubenthaler (1971), reported the role of starch in three soft wheat flour tests studied using reconstituted flours. They showed that, reconstituted flour with barley starch proved very good for cakes and cookies and had viscosities close to this of flour with wheat starch. These results indicate that starch must have certain physical and chemical properties for satisfactory performance. Dhingar and Jood (2002), studied the physico-chemical and nutritional properties of cereal pulse blends for bread making. Supplementation of soy (full fat and defatted) and barley flours to wheat flour at 5, 10, 15 and $20 \%$ levels were studied. They found that, All the blends at $20 \%$ levels were found nutritionally superior, but breads prepared from them found organoleptically unacceptable. However, addition of $15 \%$ barley flour, $10 \%$ full fat soy flour, $10 \%$ defatted soy flour, $15 \%$ full fat soy flour+ barley flour and $15 \%$ defatted soy flour+ barley flour to wheat flour not only increased the total protein, glutelin (protein fraction), total lysine, dietary fibre and $\beta$ glucan contents of cereal-pulse blends for bread making, but, could also produce a product of acceptable quality. Hruskova et al. (2003), studied the improved effect of malt flour on the rheological properties of full dough system during the proofing, the oven spring, and the baking process. The influence of small amounts of malt flour on the proofing stability was significant. The increase was about $40 \%$ for both sets of flour. The proofing time was not prolonged as significantly as the dough elasticity in all samples. The dough behavior during oil baking in the oven rise tests was influenced by the addition of malt at an important level, similarly as the specific bread volume in the baking test, and they found the bread shape ratio increased insignificantly by the malt fortification. A significant correlation was obtained between the oven spring parameters and the baking test results, but as far as the maturograph characteristics are concerned, their relationship to the bread volume depends on flour quality. Dhingra and Jood (2004), studied the effect of supplementation on the functional, baking, and organoleptic characteristics of bread. they indicated that the bread volume decreased with increasing amount of non-wheat flour substitution. It may be concluded that the substitution of wheat flour with soybean and barley flour up to an amount equivalent to $10 \%$ of full-fat and defatted soy flour, $15 \%$ for barley flour, full-fat soy + barley flour and defatted soy + barley flour produced acceptable bread loaves with good organoleptic characteristics. Ereifej et al. (2006), suggested that, barley flour can be used to replace $30 \%$ to $45 \%$ of wheat flour in Balady bread loaves without adversely affecting the consumer acceptability of the bread. However, when increasing barley flour content beyond these limits, the resulting bread loaves are found to be harder, darker in color, and nonuniformly shaped; therefore, less acceptable bread. Sullivan et al. (2010), produced doughs and breads using pearled barley flour (PBF) in different ratios $(30,50,70$ and $100 \%)$ to wheat flour. A $100 \%$ wheat flour formulation was used as a control. They found that, a low protein content usually signifies a reduced baking quality, so this result would suggest that, the inclusion of barley flour into the bread formulation would decrease the quality of the resulting breads. Increasing the pearled barley flour concentration significantly decreased the volume of the breads. The results would indicate that, there is potential for a bread product containing up to $50 \%$ barley flour. Lin et al. (2012) illustrated the effect of barley on the mechanical properties of wheat flour dough, which was important for determining both the properties of the dough during processing and the quality of the end-product. They used steamed bread incorporated with barley flour at 10, 20 and 30\% substitution levels. They found that, increased levels of barley flour caused significant decreases in the specific volume, brightness, and whiteness index of steamed bread, as well as increases in hardness and chewiness. Hussein et al. (2013), focused on substituting a part of wheat flour (WF) with whole meal barley (WBF), gelatinized corn flour (GCF) and both of them in balady bread. It is found that, WF supplemented with WBF: GCF (30:15\%) did not affected technological quality of balady bread and improved its nutritive values. Mariotti et al. (2014), showed that, the barley sourdoughs investigated could be used to obtain barley bread with enhanced nutritional value. Furthermore, despite the lower specific volume and denser crumb of barley breads with respect to wheat bread, no significant differences were seen in the degree of liking among the three breads after baking and during 
shelf-life, thus confirming the possibility for successful exploitation of barley flour in the baking industry. Bhatt and Gupta (2015), prepared healthy bread, enriched with protein and fiber, from composite flours formulations, to evaluate nutritional, phytochemical activity, functional and physiochemical properties of the flours and breads. Four different proportions of composite flours were used, i.e., 1) $50 \%$ refined wheat, $10 \%$ chickpea, $10 \%$ buckwheat, $10 \%$ sorghum, $10 \%$ sprouted barley and $10 \%$ sprouted wheat (MI), 2) $50 \%$ whole wheat, $10 \%$ chickpea, $10 \%$ buckwheat $10 \%$ sorghum, $10 \%$ sprouted barley and $10 \%$ sprouted wheat (MII), 3) 65\% refined wheat, 5\% chickpea, $5 \%$ buckwheat $5 \%$ sorghum, $5 \%$ sprouted barley, $5 \%$ sprouted wheat, $5 \%$ corn flour and $5 \%$ defatted soy flour (RWI), 4) $65 \%$ whole wheat, $5 \%$ chickpea, 5\% buckwheat, 5\% sorghum, 5\% sprouted wheat, $5 \%$ sprouted barley, $5 \%$ corn flour and $5 \%$ defatted soy flour (RWII). They concluded that, the use of the formulated composite flour might be considered in the preparation of the bread. Lalit and Kochhar (2017), showed that, incorporation of barely flour at 25 percent level and germinated fenugreek seed powder at 5 percent level was highly acceptable. Supplemented bread showed increase in protein, fiber and reducing sugars. Value added bakery products were recommended for nutritional and health benefits because they were cost effective, nutritious and helps to manage different diseases.

Table 12: Effect of sorghum flour and pulses Flour substitution on loaf diameter after baking of flour blends of wheat cultivars

\begin{tabular}{|l|l|l|l|l|}
\hline \multirow{2}{*}{\multicolumn{2}{|c|}{ Flour blends }} & \multicolumn{4}{c|}{ Wheat cultivar } \\
\cline { 2 - 5 } & \multicolumn{1}{|c|}{ Misr2 } & \multicolumn{1}{c|}{ Giza171 } & \multicolumn{1}{c|}{ Gimmeza11 } & \multicolumn{1}{c|}{ Combined } \\
\hline WF 100 \% & 20.020 & 20.060 & 18.940 & 19.673 \\
\hline WF+ 10\% SF & 20.237 & 18.257 & 19.290 & 19.261 \\
\hline WF+10\% SF+ 5\% Fen & 19.780 & 18.177 & 18.930 & 18.962 \\
\hline WF+10\% SF+ 5\% Soy & 20.320 & 17.187 & 18.930 & 18.812 \\
\hline WF+ 20\% SF & 17.057 & 16.777 & 18.533 & 17.456 \\
\hline WF+ 20\% SF+ 5\% Fen & 17.207 & 16.093 & 18.887 & 17.396 \\
\hline WF+ 20\% SF+ 5\% Soy & 15.277 & 16.517 & 18.870 & 16.888 \\
\hline WF+ 30\% SF & 19.773 & 19.010 & 19.233 & 19.339 \\
\hline WF+ 30\% SF+ 5\% Fen & 19.873 & 17.777 & 19.590 & 19.080 \\
\hline WF+ 30\% SF+ 5\% Soy & 19.893 & 18.147 & 20.930 & 19.657 \\
\hline
\end{tabular}

WF; Wheat Flour SF; Sorghum Flour

\section{Barley flour substitution:}

Barley flour and pulses flour substitution effects on loaf diameter after baking were presented in Table 13. Substitution of wheat flour by $10 \%$ barley flour blend gave significantly lower loaf diameter (19.67 vs. $18.17 \mathrm{~cm}$ for full wheat flour and wheat flour $+10 \%$ barley flour, respectively). That effect was true in Giza171 and Gimmeza11 wheat cultivars flour $(17.21$ and $17.71 \mathrm{~cm}$ for the former and the latter, respectively). Also, paradoxically to the other studied wheat cultivars, the blend of Gimmeza11 wheat flour $+10 \%$ barley flour $+5 \%$ fenugreek flour showed significantly lower loaf diameter after baking $(18.01 \mathrm{~cm})$. Raising the level of barley flour substitution to $20 \%$ of Misr2 and Giza171 wheat flour cultivars, resulted in significantly lower loaf diameter after baking (17.53and $18.00 \mathrm{~cm}$ for Misr2 and Giza171 wheat cultivars, respectively). Meanwhile, Gimmeza11 wheat flour blend with $20 \%$ barley flour maintained higher loaf diameter $(20.14 \mathrm{~cm})$. Addition substitution by $5 \%$ fenugreek or $5 \%$ soybean flour to wheat $20 \%$ barley flours blends, resulted in sig- nificantly lower loaf diameter after baking (16.22 and $16.55 \mathrm{~cm}$ for blend of $20 \%$ barley flour $+5 \%$ fenugreek flour and $20 \%$ barley flour $+5 \%$ soybean flour, respectively). The least loaf diameter after baking were expressed by Misr2 wheat flour substituted by $20 \%$ barley flour and $5 \%$ fenugreek or $5 \%$ soybean flours $(14.55$ and $15.18 \mathrm{~cm}$ for the former and the latter, respectively). Blends of wheat flour substituted by $30 \%$ barley flour maintained similar loaf diameter after baking to that of full any of the studied wheat cultivars flour.

Niffenegger (1964) showed that, the starch and proteins of barley and wheat flour behave differently. The starch of barley flour has less thickening capacity and less water absorption than wheat. The protein has less gluten-like strength. Baked products which are dependent on glutenlike strength are made less successfully from barley flour than from wheat flour. Appearance and flavor are usually affected by the addition of barley flour.Sollars and Rubenthaler (1971), reported the role of starch in three soft wheat flour tests studied using reconstituted flours. They showed that, re- 
constituted flour with barley starch proved very good for cakes and cookies and had viscosities close to this of flour with wheat starch. These results indicate that starch must have certain physical and chemical properties for satisfactory performance. Dhingar and Jood (2002), studied the physico-chemical and nutritional properties of cereal pulse blends for bread making. Supplementation of soy (full fat and defatted) and barley flours to wheat flour at 5, 10, 15 and $20 \%$ levels were studied. They found that, All the blends at $20 \%$ levels were found nutritionally superior, but breads prepared from them found organoleptically unacceptable. However, addition of $15 \%$ barley flour, $10 \%$ full fat soy flour, $10 \%$ defatted soy flour, $15 \%$ full fat soy flour+ barley flour and $15 \%$ defatted soy flour+ barley flour to wheat flour not only increased the total protein, glutelin (protein fraction), total lysine, dietary fibre and $\beta$ glucan contents of cereal-pulse blends for bread making, but, could also produce a product of acceptable quality.Hruskova et al. (2003), studied the improved effect of malt flour on the rheological properties of full dough system during the proofing, the oven spring, and the baking process. The influence of small amounts of malt flour on the proofing stability was significant. The increase was about $40 \%$ for both sets of flour. The proofing time was not prolonged as significantly as the dough elasticity in all samples. The dough behavior during oil baking in the oven rise tests was influenced by the addition of malt at an important level, similarly as the specific bread volume in the baking test, and they found the bread shape ratio increased insignificantly by the malt fortification. A significant correlation was obtained between the oven spring parameters and the baking test results, but as far as the maturograph characteristics are concerned, their relationship to the bread volume depends on flour quality. Dhingra and Jood (2004), studied the effect of supplementation on the functional, baking, and organoleptic characteristics of bread. they indicated that the bread volume decreased with increasing amount of non-wheat flour substitution. It may be concluded that the substitution of wheat flour with soybean and barley flour up to an amount equivalent to $10 \%$ of full-fat and defatted soy flour, $15 \%$ for barley flour, full-fat soy + barley flour and defatted soy + barley flour produced acceptable bread loaves with good organoleptic characteristics. Ereifej et al. (2006), suggested that, barley flour can be used to replace $30 \%$ to $45 \%$ of wheat flour in Balady bread loaves without adversely affecting the consumer acceptability of the bread. However, when increasing barley flour content beyond these limits, the resulting bread loaves are found to be harder, darker in color, and non-uniformly shaped; therefore, less acceptable bread. Sullivan et al. (2010), produced doughs and breads using pearled barley flour (PBF) in different ratios $(30,50,70$ and $100 \%)$ to wheat flour. A $100 \%$ wheat flour formulation was used as a control. They found that, a low protein content usual- ly signifies a reduced baking quality, so this result would suggest that, the inclusion of barley flour into the bread formulation would decrease the quality of the resulting breads. Increasing the pearled barley flour concentration significantly decreased the volume of the breads. The results would indicate that, there is potential for a bread product containing up to $50 \%$ barley flour. Lin et al. (2012) illustrated the effect of barley on the mechanical properties of wheat flour dough, which was important for determining both the properties of the dough during processing and the quality of the end-product. They used steamed bread incorporated with barley flour at 10, 20 and 30\% substitution levels. They found that, increased levels of barley flour caused significant decreases in the specific volume, brightness, and whiteness index of steamed bread, as well as increases in hardness and chewiness. Hussein et al. (2013), focused on substituting a part of wheat flour (WF) with whole meal barley (WBF), gelatinized corn flour (GCF) and both of them in balady bread. It is found that, WF supplemented with WBF: GCF (30:15\%) did not affected technological quality of balady bread and improved its nutritive values. Mariotti et al. (2014), showed that, the barley sourdoughs investigated could be used to obtain barley bread with enhanced nutritional value. Furthermore, despite the lower specific volume and denser crumb of barley breads with respect to wheat bread, no significant differences were seen in the degree of liking among the three breads after baking and during shelf-life, thus confirming the possibility for successful exploitation of barley flour in the baking industry. Bhatt and Gupta (2015), prepared healthy bread, enriched with protein and fiber, from composite flours formulations, to evaluate nutritional, phytochemical activity, functional and physiochemical properties of the flours and breads. Four different proportions of composite flours were used, i.e., 1) $50 \%$ refined wheat, $10 \%$ chickpea, $10 \%$ buckwheat, $10 \%$ sorghum, $10 \%$ sprouted barley and $10 \%$ sprouted wheat (MI), 2) $50 \%$ whole wheat, $10 \%$ chickpea, $10 \%$ buckwheat $10 \%$ sorghum, $10 \%$ sprouted barley and $10 \%$ sprouted wheat (MII), 3) 65\% refined wheat, 5\% chickpea, $5 \%$ buckwheat $5 \%$ sorghum, $5 \%$ sprouted barley, $5 \%$ sprouted wheat, $5 \%$ corn flour and $5 \%$ defatted soy flour (RWI), 4) $65 \%$ whole wheat, $5 \%$ chickpea, 5\% buckwheat, 5\% sorghum, 5\% sprouted wheat, $5 \%$ sprouted barley, $5 \%$ corn flour and $5 \%$ defatted soy flour (RWII). They concluded that, the use of the formulated composite flour might be considered in the preparation of the bread.Lalit and Kochhar (2017), showed that, incorporation of barely flour at 25 percent level and germinated fenugreek seed powder at 5 percent level was highly acceptable. Supplemented bread showed increase in protein, fiber and reducing sugars. Value added bakery products were recommended for nutritional and health benefits because they were cost effective, nutritious and helps to manage different diseases. 
Table 13: Effect of barley flour and pulses flour substitution on loaf diameter after baking of flour blends of wheat cultivars

\begin{tabular}{|l|c|c|c|c|}
\hline \multirow{2}{*}{ Flour blends } & \multicolumn{4}{c|}{ Wheat cultivar } \\
\cline { 2 - 5 } & Misr2 & Giza171 & Gimmeza11 & Combined \\
\hline WF 100 \% & 20.020 & 20.060 & 18.940 & 19.673 \\
\hline WF+ 10\% BF & 19.680 & 17.120 & 17.713 & 18.171 \\
\hline WF+10\% BF+ 5\% Fen & 20.503 & 19.643 & 18.007 & 19.384 \\
\hline WF+10\% BF+ 5\% Soy & 19.643 & 17.513 & 17.737 & 18.298 \\
\hline WF+ 20\% BF & 17.530 & 18.000 & 20.143 & 18.558 \\
\hline WF+ 20\% BF+ 5\% Fen & 14.550 & 16.890 & 17.220 & 16.220 \\
\hline WF+ 20\% BF+ 5\% Soy & 15.177 & 16.587 & 17.890 & 16.551 \\
\hline WF+ 30\% BF & 19.890 & 18.860 & 19.867 & 19.539 \\
\hline WF+ 30\% BF+ 5\% Fen & 19.393 & 20.587 & 19.600 & 19.860 \\
\hline WF+ 30\% BF+ 5\% Soy & 18.933 & 18.927 & 18.077 & 18.646 \\
\hline
\end{tabular}

WF; Wheat Flour BF; Barley Flour $\quad$ Fen; Fenugreek Flour Soy; Soybean flour

Orthogonal comparisons between different levels of rice flour substitution to wheat flour reflected on loaf diameter after baking were presented in Table 14. Flour blends substituted by $10 \%$ vs. $20 \%$ rice flour was associated with reduction in loaf diameter after baking reached $0.531,0.171$ and $0.198 \mathrm{~cm}$ for wheat cultivars Misr2, Giza171 and Gimmeza11, respectively. That reduction was

Table 14: Orthogonal comparisons between different levels of rice flour substitution to wheat flour reflected on loaf diameter after baking of the flour blend

\begin{tabular}{|l|c|c|c|c|c|c|}
\hline \multirow{2}{*}{ Comparisons } & \multicolumn{7}{|c|}{ Wheat cultivar } \\
\cline { 2 - 7 } & \multicolumn{2}{|c|}{ Misr2 } & \multicolumn{2}{c|}{ Giza171 } & \multicolumn{2}{c|}{ Gimmeza11 } \\
\cline { 2 - 7 } & Effect & Signifi- & Effect & Signifi- & Effect & Signifi- \\
\hline $\begin{array}{l}\text { WF+ 10\% RF v.s } \\
\text { WF+20\% RF }\end{array}$ & -0.531 & 0.012 & -0.170 & 0.374 & -0.193 & 0.376 \\
\hline $\begin{array}{l}\text { WF+ 20\% RF v.s } \\
\text { WF+30\% RF }\end{array}$ & 0.716 & 0.001 & -0.557 & 0.050 & -0.708 & 0.028 \\
\hline
\end{tabular}

WF; Wheat Flour RF; Rice Flour Fen; Fenugreek Flour Soy; Soybean flour

Orthogonal comparison between blends of sorghum flour substitution and its effect on loaf diameter after baking were presented in Table 15 . Raising the level of sorghum flour substitution from 10 to $20 \%$ of wheat flour, reduced loaf diameter after baking by $1.799(\mathrm{p} \geq 0.0001), 0.706(\mathrm{p} \geq$ $0.014)$ and $0.370 \quad(p \geq 0.208) \mathrm{cm}$ for blends of Misr2, Giza171 and Gimmeza11 wheat flour, respectively). Meanwhile, additional substitution of wheat flour by sorghum flour at $30 \%$ level enlarged loaf diameter after baking by $1.667(\mathrm{p} \geq$ $0.0001), 0.924(\mathrm{p} \geq 0.002)$ and $0.577(\mathrm{p} \geq 0.07) \mathrm{cm}$ for Misr2, Giza171 and Gimmeza11 cultivars, respectively).

Table 15: Orthogonal comparisons between different levels of sorghum flour substitution to wheat flour reflected on loaf diameter after baking of the flour blend

\begin{tabular}{|l|c|c|c|c|c|c|}
\hline \multirow{2}{*}{ Comparisons } & \multicolumn{7}{|c|}{ Wheat cultivar } \\
\cline { 2 - 7 } & \multicolumn{2}{|c|}{ Misr2 } & \multicolumn{2}{c|}{ Giza171 } & \multicolumn{2}{c|}{ Gimmeza11 } \\
\cline { 2 - 7 } & Effect & Signifi- & Effect & Signifi- & Effect & Signifi- \\
\hline $\begin{array}{l}\text { WF+ 10\% SF } v . s \\
\text { WF+20\% SF }\end{array}$ & -1.799 & 0.000 & -0.706 & 0.014 & -0.370 & 0.208 \\
\hline $\begin{array}{l}\text { WF+ 20\%SF v.s } \\
\text { WF+30\% SF }\end{array}$ & 1.667 & 0.000 & 0.924 & 0.002 & 0.577 & 0.071 \\
\hline
\end{tabular}

WF; Wheat Flour

SF; Sorghum Flour

Fen; Fenugreek Flour

Soy; Soybean flour 
Comparison between levels of barley flour substitution on loaf diameter after baking(Table 16) showed that, $20 \%$ level of barley flour substitution reduced loaf diameter after baking of Misr2 blends by 2.095 ( $\mathrm{p} \geq 0.0001)$ and Giza171 blends by $0.467(\mathrm{p} \geq 0.09) \mathrm{cm}$. While, opposite effect was noticed with Gimmeza11 blends, where, loaf di- ameter increased by $0.299 \mathrm{~cm} \quad(\mathrm{p} \geq 0.907)$. The highest level of barley flour substitution (30\%) was associated with reduction in loaf diameter after baking reached $1.827 \mathrm{~cm}(\mathrm{p} \geq 0.0001)$ in Misr2 blends, $1.149 \mathrm{~cm}(\mathrm{p} \geq 0.0001)$ in Giza171 blends and $0.382 \mathrm{~cm}(\mathrm{p} \geq 0.23)$ in Gimmeza11 blends.

Table 16: Orthogonal comparisons between different levels of barley flour substitution to wheat flour reflected on loaf diameter after baking of the flour blend.

\begin{tabular}{|l|c|c|c|c|c|c|}
\hline \multirow{2}{*}{ Comparisons } & \multicolumn{7}{|c|}{ Wheat cultivar } \\
\cline { 2 - 7 } & \multicolumn{2}{|c|}{ Misr2 } & \multicolumn{2}{c|}{ Giza171 } & \multicolumn{2}{c|}{ Gimmeza11 } \\
\cline { 2 - 7 } & Effect & Signifi- & Effect & Signifi- & Effect & Signifi- \\
\hline $\begin{array}{l}\text { WF+ 10\% BF } v \cdot s \\
\text { WF+20\% BF }\end{array}$ & -2.095 & 0.000 & -0.467 & 0.098 & 0.299 & 0.907 \\
\hline $\begin{array}{l}\text { WF+20\%BFv.s } \\
\text { WF+30\%BF }\end{array}$ & 1.827 & 0.000 & 1.149 & 0.000 & 0.382 & 0.230 \\
\hline
\end{tabular}

WF; Wheat Flour

BF; Barley Flour

\section{Type of cereal:}

Orthogonal comparisons between blends of different cereal substitution regardless of the level and type of pulse flour, reflected on loaf diameter after baking were shown in Table 17. Blends with rice flour $v s$. sorghum flour positively affected loaf diameter after baking by $0.364 \mathrm{~cm}(\mathrm{p} \geq 0.003)$ for

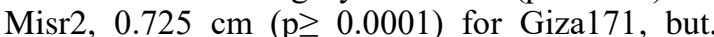

Fen; Fenugreek Flour

Soy; Soybean flour inversely affected loaf diameter after baking in Gimmeza11 by $0.221 \mathrm{~cm}(\mathrm{p} \geq 0.229)$. Also, the comparison between rice flour blends and barley flour blends showed that, the former had larger loaf diameter after baking by $(0.593 \mathrm{~cm}(\mathrm{p} \geq$ $0.0001)$ for Misr2, $0.381 \mathrm{~cm} \mathrm{(} \mathrm{p} \geq 0.021)$ for Gi$\mathrm{za} 171$ and $0.165 \mathrm{~cm}(\mathrm{p} \geq 0.826)$ for Gimmeza11 cultivar, respectively).

Table 17: Orthogonal comparison for the effect of pulse flours supplementation to wheat local cereals flours on loaf diameter after baking of flour blends

\begin{tabular}{|l|c|c|c|c|c|c|}
\hline \multirow{2}{*}{ Comparisons } & \multicolumn{6}{c|}{ Wheat cultivar } \\
\cline { 2 - 7 } & \multicolumn{2}{|c|}{ Misr2 } & \multicolumn{2}{c|}{ Giza171 } & \multicolumn{2}{c|}{ Gimmeza11 } \\
\cline { 2 - 7 } & Effect & Signifi- & Effect & Signifi- & Effect & Signifi- \\
\hline $\begin{array}{l}\text { WF+ RF } v . s \\
\text { WF+SF }\end{array}$ & -0.364 & 0.003 & -0.725 & 0.000 & 0.221 & 0.229 \\
\hline $\begin{array}{l}\text { WF+RFv.s } \\
\text { WF+BF }\end{array}$ & -0.593 & 0.000 & -0.381 & 0.021 & -0.165 & 0.826 \\
\hline
\end{tabular}

\section{Pulse flour substitution:}

Comparison between blends that contained fenugreek flour $v s$. blends contained soybean flour reflected on loaf diameter after baking were illustrated in Table 18. Substitution by the fenugreek flour $v s$. soybean flour reduced loaf diameter by $0.169 \mathrm{~cm}(\mathrm{p} \geq 0.135)$ in Misr2 blends and $0.219 \mathrm{~cm}$ $(\mathrm{p} \geq 0.156)$ in Giza171 blends. While, soybean flour blends in Gimmeza11 wheat cultivar had larger loaf diameter after baking by $0.045 \mathrm{~cm} \mathrm{(p \geq}$ $0.067)$. In the meantime, blends that contained $5 \%$ fenugreek $+5 \%$ soybean flours gave narrower loaf diameter by $0.108 \mathrm{~cm}(\mathrm{p} \geq 0.028)$ in blends in Misr2 and $0.245 \mathrm{~cm}(\mathrm{p} \geq 0.0001)$ in blends of $\mathrm{Gi}$ za171, While, blends of Gimmeza11 flours besides fenugreek and soybean flours gave larger loaf diameter after baking amounted to $0.099(\mathrm{p} \geq 0.183)$. Also, comparison between flour blends that included fenugreek and soybean flours vs. blends that included soybean flour was associated with reduction in loaf diameter after baking reached
$0.140 \mathrm{~cm}(\mathrm{p} \geq 0.005)$ in Misr2 and $0.285 \mathrm{~cm}(\mathrm{p} \geq$ 0.0001 ) in Giza171 wheat cultivars. While, blends of Gimmeza11 showed larger loaf diameter after baking when substituted by fenugreek and soybean flour $(0.107 \mathrm{~cm}(\mathrm{p} \geq 0.151)$.

Means of loaf weight after baking as affected by rice and pulses flours substitution were presented in Table 19. Loaf weight after baking stand for moisture retention by loaf matrix which is affected by the percentage and nature of starch granules. Substitution of wheat flour by $10 \%$ rice flour significantly gave heavier. Loaf (89.32 vs. $83.92 \mathrm{~g}$ for wheat flour substituted by $10 \%$ rice flour vs. full wheat flour). This might indicate higher moisture retention due to the nature of rice starch granules. Additional substitution of wheat flour by $5 \%$ fenugreek or soybean flours, yielded significantly similar loaf weight $(0.36$ and $88.90 \mathrm{~g}$. for blend of wheat flour substituted by $10 \%$ rice $+5 \%$ fenugreek flours and blends of wheat flour substituted by $10 \%$ rice $+5 \%$ soybean flours, respectively). 
Table 18: Orthogonal comparison for the effect of pulse flours Substitution to wheat local cereals flours on loaf diameter after baking of flour blend

\begin{tabular}{|l|c|c|c|c|c|c|}
\hline \multirow{2}{*}{ Comparisons } & \multicolumn{7}{|c|}{ Wheat cultivar } \\
\cline { 2 - 7 } & \multicolumn{2}{|c|}{ Misr2 } & \multicolumn{2}{c|}{ Giza171 } & \multicolumn{2}{c|}{ Gimmeza11 } \\
\cline { 2 - 7 } & Effect & Significance & Effect & Significance & Effect & Significance \\
\hline $\begin{array}{l}\text { WF+ (RF, SF, BF)+Fen } \\
v s . \text { WF+(RF,SF,BF)+SO }\end{array}$ & -0.169 & 0.135 & -0.219 & 0.156 & 0.045 & 0.067 \\
\hline $\begin{array}{l}\text { WF +Fen +SO } v s . \\
\text { WF + Fen }\end{array}$ & 0.108 & 0.028 & 0.245 & 0.000 & -0.099 & 0.183 \\
\hline $\begin{array}{l}\text { WF+ Fen+ SO } v s . \\
\text { WF+SO }\end{array}$ & 0.140 & 0.005 & 0.285 & 0.000 & -0.107 & 0.151 \\
\hline
\end{tabular}

Substitution of wheat flour by $20 \%$ rice flour yielded variable loaf weights after baking, depending on the type of wheat cultivar. Misr2 wheat flour blend with $20 \%$ rice flour, gave significantly lower loaf weight after baking (77.12 g). While, Giza171 wheat flour blend with $20 \%$ rice flour significantly yielded heavier loaf weight after baking $(91.57 \mathrm{~g})$. The opposite was true for Gimmeza11 wheat flour blend with $20 \%$ rice flour, since, significantly lower loaf weight after baking was obtained relative to full wheat flour $(84.07 \mathrm{vs}$. 93.66 for blend with $20 \%$ rice flour vs. full wheat flour of cultivar Gimmeza11). Additional substitution of wheat flour by $5 \%$ fenugreek flour (blend of $20 \%$ rice flour $+5 \%$ fenugreek flour) resulted in a significant increase in loaf weight in Misr2 wheat blend (84.39 g.) and significantly similar loaf weight in both of Giza171 and Gimmeza11 wheat blends $(89.29$ and $85.31 \mathrm{~g}$. for the former and the latter, respectively. Replacing soybean and fenugreek flour in blends of wheat $+20 \%$ rice flour significantly reduced loaf weight after baking in Misr2 wheat flour blend (80.41 g.), but, maintained loaf weight in Giza171 and Gimmeza11 flour blends (88.97 and $84.47 \mathrm{~g}$. for the cultivars, respectively).

Higher level of rice flour substitution to wheat flour $(30 \%)$ gave significantly similar loaf wheat to that of $20 \%$ rice flour substitution $(85.70$ g.). Additional substitution by $5 \%$ fenugreek flour or 5\% soybean flour improved loaf weight after baking to 89.26 and $88.29 \mathrm{~g}$., respectively.

Table 19: Effect of rice flour and pulses flour substitution on loaf weight after baking of flour blends of wheat cultivars

\begin{tabular}{|l|c|c|c|c|}
\hline \multirow{2}{*}{ Flour blends } & \multicolumn{4}{c|}{ Wheat cultivar } \\
\cline { 2 - 5 } & Misr2 & Giza171 & Gimmeza11 & Combined \\
\hline WF 100\% & 81.210 & 76.903 & 93.660 & 83.924 \\
\hline WF+ 10\% RF & 85.553 & 88.213 & 94.197 & 89.321 \\
\hline WF+10\% RF+ 5\% Fen & 92.247 & 86.940 & 91.907 & 90.364 \\
\hline WF+10\% RF+ 5\% Soy & 88.877 & 85.170 & 92.660 & 88.902 \\
\hline WF+ 20\% RF & 77.120 & 91.567 & 84.073 & 84.253 \\
\hline WF+ 20\% RF+ 5\% Fen & 84.390 & 89.290 & 85.310 & 86.330 \\
\hline WF+ 20\% RF+ 5\% Soy & 80.410 & 88.973 & 84.473 & 84.619 \\
\hline WF+ 30\% RF & 81.967 & 86.927 & 88.203 & 85.699 \\
\hline WF+ 30\% RF+ 5\% Fen & 91.187 & 82.640 & 93.953 & 89.260 \\
\hline WF+ 30\% RF+ 5\% Soy & 84.677 & 88.940 & 91.257 & 88.291 \\
\hline
\end{tabular}

WF; Wheat Flour RF; Rice Flour

\section{Sorghum flour substitution:}

Sorghum flour substitution to wheat flour at $10 \%$ level, significantly improved loaf weight after baking to $86.34,87.59$ and $88.41 \mathrm{~g}$. for Misr2, Giza171 and Gimeza11 wheat flours, respectively. Additional substitution by $5 \%$ fenugreek flour improved loaf weight after baking for Misr2 wheat flour blend (90.52 g.) and Gimmeza11 wheat flour
Fen; Fenugreek Flour Soy; Soybean flour blend (94.94 g.). soybean flour at 5\% level with $10 \%$ sorghum flour substitution, gave additional increase in loaf weight (94.60 g. for Misr2 wheat blend), whereas, that response was not recorded in case of Giza171 or Gimmeza11 wheat flours.

Substitution of wheat flour by $20 \%$ sorghum flour gave proportional increase in loaf weight relative to the level of $10 \%$ sorghum flour substitu- 
tion. Those increases in loaf weight reached 89.39, 88.64 and 87.40 g. with Misr2, Giza171 and Gimmeza11 wheat flours, respectively. Additional substitution to wheat flour by $5 \%$ fenugreek flour increased loaf weight after baking to 93.48, 88.63 and $96.99 \mathrm{~g}$. with Misr2, Giza171 and Gimmeza11 wheat cultivars, respectively. Replacing soybean flour to fenugreek flour in $20 \%$ sorghum wheat flour blends had not affected loaf weight of different wheat cultivars flour blends.

The highest level of sorghum flour substitution to wheat flour (30\%) surpassed $20 \%$ level of substitution in gain in loaf weight after baking (94.66, 92.26 and 91.12 g. with Misr2, Giza171 and Gimmeza11 wheat flour cultivars, respectively). Additional substitution by any of 5\% fenugreek or soybean flours gave lower loaf weight after baking, with significantly lower values in Misr2 and Giza171 flour blends (88.89 and 88.84 g., respectively). It was valuable to notice that, all levels of sorghum flour replacement to what flours, gave significantly higher loaf weight after baking across all studied wheat flour cultivars.

Table20: Effect of sorghum flour and pulses flour substitution on loaf weight after baking of flour blends of wheat cultivars

\begin{tabular}{|l|c|c|c|c|}
\hline \multirow{2}{*}{ Flour blends } & \multicolumn{4}{c|}{ Wheat cultivar } \\
\cline { 2 - 5 } & Misr2 & Giza171 & Gimmeza11 & Combined \\
\hline WF 100 \% & 81.210 & 76.903 & 93.660 & 83.924 \\
\hline WF+ 10\% SF & 86.337 & 87.587 & 88.407 & 87.443 \\
\hline WF+10\% SF+ 5\% Fen & 90.523 & 85.240 & 94.943 & 90.236 \\
\hline WF+10\% SF+ 5\% Soy & 94.597 & 86.190 & 92.500 & 91.096 \\
\hline WF+ 20\% SF & 89.393 & 88.643 & 87.403 & 88.480 \\
\hline WF+ 20\% SF+ 5\% Fen & 93.480 & 88.633 & 96.997 & 93.037 \\
\hline WF+ 20\% SF+ 5\% Soy & 90.503 & 89.057 & 96.247 & 92.269 \\
\hline WF+ 30\% SF & 94.657 & 92.263 & 91.123 & 92.35 \\
\hline WF+ 30\% SF+ 5\% Fen & 92.377 & 90.253 & 87.183 & 89.938 \\
\hline WF+ 30\% SF+ 5\% Soy & 88.89 & 88.843 & 95.920 & 91.220 \\
\hline
\end{tabular}

WF; Wheat Flour SF; Sorghum Flour

Effect of barley flour and pulses flour substitution on loaf weight after baking were illustrated in Table 21. Barley flour substitution to wheat flour at $10 \%$ level gave significantly heavier loaf weight with Misr2 (85.88 g.), Giza171 (85.99 g.) and Gimmeza11 (88.81 g.) wheat cultivars. Additional substitution to wheat flour by $5 \%$ fenugreek flour, gave substantial increase in loaf weight after baking $(88.97,87.91$ and 90.29 g. with Misr2, Giza171 and Gimmeza11 wheat cultivars, respectively). Replacing soybean flour at 5\% level to fenugreek flour in $10 \%$ barley/wheat blends gave similar loaf weight after baking. Raising the level of barley flour substitution to $20 \%$ of wheat flour, surpassed the $10 \%$ level of substitution in loaf weight after baking $(87.51,87.32$ and $88.65 \mathrm{~g}$. for Misr2, Giza171 and Gimmeza11 wheat cultivars, respectively). Additional substitution by $5 \%$ fenugreek or soybean flour pulse $20 \%$ barley flour gave an improvement in loaf weight after baking, although had not reached the level of significance.

Maximum improvement in loaf weight after baking were recorded with $30 \%$ level of barley
Fen; Fenugreek Flour

Soy; Soybean flour

flour substitution wheat flour $(93.23,89.88$ and 91.61 g. with Misr2, Giza171 and Gimmeza11 wheat cultivars, respectively).

Orthogonal comparisons between different levels of rice flour substitution to wheat flour on loaf weight after baking were presented in Table 22 . Wheat flour blends contained $10 \%$ level of rice flour substitution, surpassed blends contained $20 \%$ rice flour in loaf weight after baking by $4.126 \mathrm{~g}$. ( $\mathrm{p} \geq$ 0.0001 ) for Misr2 wheat cultivar, 4.151 g. ( $\mathrm{p} \geq$ 0.0001 ) for Gimmeza11 wheat cultivar. While, the opposite was true for Giza171 wheat cultivar, since, loaf weight after baking lost 1.584 g. ( $\geq \geq 0.001)$ when rice flour substitution level reached $20 \%$.

Meanwhile, the different between $20 \%$ and $30 \%$ levels of rice flour substitution, represented by loaf weight after baking, showed that loaf weight increased by $2.652 \mathrm{~g} .(\mathrm{p} \geq 0.0001)$ and 0.333 g. ( $p \geq 0.006)$ for wheat cultivars Misr2 and Gimmeza11, respectively. While Giza171 wheat cultivar expressed lose in loaf weight reached 1.887 g. ( $\mathrm{p} \geq 0.002)$. 
Table 21: Effect of barley flour and pulses flour substitution on loaf weight after baking of flour blends of wheat cultivars.

\begin{tabular}{|l|c|c|c|c|}
\hline \multirow{2}{*}{ Flour blends } & \multicolumn{4}{c|}{ Wheat cultivar } \\
\cline { 2 - 5 } & Misr2 & Giza171 & Gimmeza11 & Combined \\
\hline WF 100 \% & 81.210 & 76.903 & 83.660 & 83.924 \\
\hline WF+ 10\% BF & 85.880 & 85.987 & 88.807 & 86.891 \\
\hline WF+10\% BF+ 5\% Fen & 88.973 & 87.907 & 90.293 & 90.724 \\
\hline WF+10\% BF+ 5\% Soy & 88.637 & 86.467 & 90.230 & 88.444 \\
\hline WF+ 20\% BF & 87.507 & 87.317 & 88.647 & 79.490 \\
\hline WF+ 20\% BF+ 5\% Fen & 89.913 & 88.887 & 88.240 & 82.347 \\
\hline WF+ 20\% BF+ 5\% Soy & 88.060 & 87.553 & 90.35 & 82.654 \\
\hline WF+ 30\% BF & 93.230 & 89.883 & 91.610 & 91.574 \\
\hline WF+ 30\% BF+ 5\% Fen & 90.903 & 88.210 & 92.663 & 90.592 \\
\hline WF+ 30\% BF+ 5\% Soy & 90.267 & 94.507 & 94.140 & 92.971 \\
\hline
\end{tabular}

WF; Wheat Flour $\quad$ BF; Barley Flour $\quad$ Fen; Fenugreek Flour $\quad$ Soy; Soybean flour

Table 22: Orthogonal comparisons between different levels of rice flour substitution to wheat flour reflected on loaf weight after baking of the flour blend.

\begin{tabular}{|l|l|l|l|l|l|l|}
\hline \multirow{2}{*}{ Comparisons } & \multicolumn{6}{|c|}{ Wheat cultivar } \\
\cline { 2 - 7 } & \multicolumn{2}{|c|}{ Misr2 } & \multicolumn{2}{c|}{ Giza171 } & \multicolumn{2}{c|}{ Gimmeza11 } \\
\cline { 2 - 7 } & \multicolumn{1}{|c|}{ Effect } & \multicolumn{1}{|c|}{ Signifi- } & Effect & \multicolumn{1}{c|}{ Signifi- } & Effect & Signifi- \\
\hline $\begin{array}{l}\text { WF+ 10\% RF v.s } \\
\text { WF+20\% RF }\end{array}$ & -4.126 & 0.000 & 1.584 & 0.010 & -4.151 & 0.000 \\
\hline $\begin{array}{l}\text { WF+ 20\% RF v.s } \\
\text { WF+30\%RF }\end{array}$ & 2.652 & 0.000 & -1.887 & 0.002 & 0.333 & 0.006 \\
\hline
\end{tabular}

WF; Wheat Flour RF; Rice Flour Fen; Fenugreek Flour Soy; Soybean flour

Comparisons between levels of sorghum flour ing the level of sorghum flour substitution to $30 \%$ substitution levels were presented in Table 23. in comparison to $20 \%$ level showed that loaf Loaf weight after baking associated with $10 \%$ lev- weight after baking increased with increasing the el of substitution surpassed those of $20 \%$ level by level of substitution to $30 \%$ level as $4.426 \mathrm{~g}$. (p $\geq$ 3.69 g. $(p \geq 0.001), 3.614$ g. ( $p \geq 0.0001)$ and $4.201 \quad 0.0001)$ for Misr2, $4.004 \mathrm{~g}(\mathrm{p} \geq 0.0001)$ for Gig. $(p \geq 0.0001)$ for Misr2, Giza171 and Gimmeza11 za171 and 3.930 g. (p $\geq 0.0001)$ for Gimmeza11, wheat cultivar flours, respectively. Contrary, rais- respectively.

Table23: Orthogonal comparisons between different levels of sorghum flour substitution to wheat flour reflected on loaf weight after baking of the flour blend

\begin{tabular}{|l|c|c|c|c|c|c|}
\hline \multirow{2}{*}{ Comparisons } & \multicolumn{6}{c|}{ Wheat cultivar } \\
\cline { 2 - 7 } & \multicolumn{2}{|c|}{ Misr2 } & \multicolumn{2}{c|}{ Giza171 } & \multicolumn{2}{c|}{ Gimmeza11 } \\
\cline { 2 - 7 } & Effect & Signifi- & Effect & Signifi- & Effect & Signifi- \\
\hline $\begin{array}{l}\text { WF+ 10\% SF } v . s \\
\text { WF+20\% SF }\end{array}$ & -3.680 & 0.000 & -3.614 & 0.000 & -4.201 & 0.000 \\
\hline $\begin{array}{l}\text { WF+ 20\%SF v.s } \\
\text { WF+30\%SF }\end{array}$ & 4.426 & 0.000 & 4.004 & 0.000 & 3.930 & 0.000 \\
\hline
\end{tabular}

Comparisons between levels of barley flour substitution to wheat flour reflected on loaf weight after baking were illustrated on Table 24. Flour blends with $10 \%$ level of barley flour substitution yielded heavier loaf weight relative to blends with $20 \%$ level of barley flour substitution. Those figures reached $3.335 \mathrm{~g}$. $(\mathrm{p} \geq 0.0001)$ for Misr2 wheat cultivar, 3.267 g. ( $p \geq 0.0001)$ for Giza171 wheat cultivar and 4.182 g. ( $\mathrm{p} \geq 0.0001)$ for Gimmeza11 cultivar. Also, substantial increase in loaf weight after baking was associated with barley substitu- tion level of $30 \%$. Those gains amounted to 5.153 g. $(p \geq 0.0001)$ for Misr2, $5.307 \mathrm{~g}$. ( $\mathrm{p} \geq 0.0001)$ for Giza171 ad 4.863 g. (p $\geq 0.0001)$ for Gimmeza11.

\section{Comparable role of cereals:}

Orthogonal comparisons for the effect of cereal flours supplementation to wheat flours were presented in Table 25. Blends of Misr2 wheat substituted with rice flour had heavy loaf weight by 1.685 g. ( $\mathrm{p} \geq 0.0001$ ) over blends substituted with sorghum flour. While, the opposite was true with blends of Giza171 (less 1.719 g. ( $p \geq 0.0001)$ and 
Gimmeza11 (less 0.295 g. ( $\mathrm{p} \geq 0.413$ ). Also, comparison between blends substituted with rice flour and those substituted by barley flour showed an increase in loaf weight after baking with barley flour reached 0.830 g. ( $\mathrm{p} \geq 0.003)$ with Misr2 cultivars. While, vas vers were noticed with Giza171 (0.830 g. ( $\mathrm{p} \geq 0.018)$ and Gimmeza11 (-0.295 g. ( $\mathrm{p} \geq$ $0.241)$.

Table 24: Orthogonal comparisons between different levels of barley flour substitution to wheat flour reflected on loaf weight after baking of the flour blend

\begin{tabular}{|l|c|c|c|c|c|c|}
\hline \multirow{2}{*}{ Comparisons } & \multicolumn{6}{c|}{ Wheat cultivar } \\
\cline { 2 - 7 } & \multicolumn{2}{|c|}{ Misr2 } & \multicolumn{2}{c|}{ Giza171 } & \multicolumn{2}{c|}{ Gimmeza11 } \\
\cline { 2 - 7 } & Effect & Signifi- & Effect & Signifi- & Effect & Signifi- \\
\hline $\begin{array}{l}\text { WF+ 10\% BF v.s } \\
\text { WF+20\% BF }\end{array}$ & -3.335 & 0.000 & -3.267 & 0.000 & -4.182 & 0.000 \\
\hline $\begin{array}{l}\text { WF+ 20\%BF v.s } \\
\text { WF+30\%BF }\end{array}$ & 5.153 & 0.000 & 5.307 & 0.000 & 4.863 & 0.000 \\
\hline
\end{tabular}

Table 25; Orthogonal comparison for the effect of pulse flours supplementation to wheat /local cereals flours on loaf weight after baking of flour blend.

\begin{tabular}{|l|l|l|l|l|l|c|}
\hline \multirow{2}{*}{ Comparisons } & \multicolumn{5}{|c|}{ Wheat cultivar } \\
\cline { 2 - 7 } & \multicolumn{2}{|c|}{ Misr2 } & \multicolumn{2}{c|}{ Giza171 } & \multicolumn{2}{c|}{ Gimmeza11 } \\
\cline { 2 - 7 } & \multicolumn{1}{|c|}{ Effect } & $\begin{array}{c}\text { Signifi- } \\
\text { cance }\end{array}$ & Effect & $\begin{array}{c}\text { Signifi- } \\
\text { cance }\end{array}$ & Effect & $\begin{array}{c}\text { Signifi- } \\
\text { cance }\end{array}$ \\
\hline $\begin{array}{l}\text { WF+ R Fv.s } \\
\text { WF+SF }\end{array}$ & 1.685 & 0.000 & -1.719 & 0.000 & -0.295 & 0.413 \\
\hline $\begin{array}{l}\text { WF +RF } v . s \\
\text { WF+ BF }\end{array}$ & 0.830 & 0.003 & -0.830 & 0.018 & -0.225 & 0.241 \\
\hline
\end{tabular}

\section{Role of pulse flour substitution:}

Orthogonal comparisons for the effect of pulse flours supplementation to wheat/local cereals flours on loaf weight after baking were presented in Table26. Wheat flour blends with local cereals substitution and fenugreek flour versus those with soybean flour showed a superiority of the former in loaf weight after baking over the latter by 0.905 g. $(p \geq 0.001)$ for Misr2 cultivar and a reduction of 0.096 g. ( $\mathrm{p} \geq 0.087)$ for Giza171 and 0.054 g. ( $\mathrm{p} \geq$ 0.015 ) for Gimmeza11 cultivar. Also, the comparison between wheat flour blends included substitution by both of fenugreek and soybean flour versus those contained fenugreek, showed an improvement in loaf weight after baking due to the additional substitution by soybean flour over fenugreek flour alone by $0.031 \mathrm{~g}$. ( $\mathrm{p} \geq 0.08)$ for Misr2, 0.488 g. $(p \geq 0.001)$ for Giza171 and $0.584 \mathrm{~g}(\mathrm{p} \geq 0.003)$ for Gimmeza11 cultivars. The comparison that illustrated the additional role of fenugreek flour when included with soybean as a substitute to wheat flour cleared that there were an improvement in loaf weight after baking associated with fenugreek substitution in blends reached $0.195(\mathrm{p} \geq$ 0.079 ) for Misr2, $0.470 \mathrm{~g}$. ( $\mathrm{p} \geq 0.001)$ for Giza171 and 0.575 g. ( $\mathrm{p} \geq 0.003)$ for Gimmeza11 cultivars.

Table 26: Orthogonal comparison for the effect of pulse flours supplementation to wheat /local cereals flours on loaf weight after baking of flour blend

\begin{tabular}{|l|c|c|c|c|c|c|}
\hline \multirow{2}{*}{ Comparisons } & \multicolumn{7}{c|}{ Wheat cultivar } \\
\cline { 2 - 7 } & \multicolumn{2}{|c|}{ Misr2 } & \multicolumn{2}{c|}{ Giza171 } & \multicolumn{2}{c|}{ Gimmeza11 } \\
\cline { 2 - 7 } & Effect & Significance & Effect & Significance & Effect & Significance \\
\hline $\begin{array}{l}\text { WF+ (RF, SF,BF) +Fen } \\
v s . \text { WF+(RF,SF,BF)+SO }\end{array}$ & -0.905 & 0.001 & 0.096 & 0.087 & 0.054 & 0.015 \\
\hline $\begin{array}{l}\text { WF +Fen +SO } v s . \\
\text { WF + Fen }\end{array}$ & 0.031 & 0.080 & 0.488 & 0.001 & 0.584 & 0.003 \\
\hline $\begin{array}{l}\text { WF+ Fen +SO } v s . \\
\text { WF+SO }\end{array}$ & 0.195 & 0.079 & 0.470 & 0.001 & 0.575 & 0.003 \\
\hline
\end{tabular}

Wheat cultivar suitability for bread making is largely influenced by its genetic make-up. The variety becomes suitable for bread-making when the ability of proteins for constructing dimensional networks of gluten during kneading is greater. Environmental factors such as nitrogen fertilization,

control measures, irrigation and season of growth modify varietal behavior. Harinder et al. (1999), showed that, pigeon pea flour was substituted at levels of $0,5,10,15,20,25 \%$ to wheat flour and whole wheat meal for bread and Chapatti making, respectively. The bread from $10 \%$ pigeon pea flour 
blend with $2-3 \%$ vital gluten and $0.5 \%$ SSL had high loaf volume and loaf quality. Blends containing $15 \%$ pigeon pea flour were acceptable for Chapatti .The increase in protein, iron and phosphorus content of the pigeon pea supplemented products could be utilized to improve the nutritional status of diets in school feeding programs and vulnerable sections of the population in developing nations where pigeon peas are available. Sharma et al. (1999), studied the effect of replacement of wheat flour with cowpea flour on rheological properties of dough and physical and sensory characteristics of some of the baked products .They indicated that, Loaf volume and overall acceptability scores of bread were reduced significantly beyond $150 \mathrm{~g} \mathrm{~kg} .1$ incorporation of cowpea flour. Abdel-Kader (2000), evaluated the physical, rheological, and baking properties of decorticated cracked broad beans-wheat composite flours and to determine the acceptability of the resulting bread. It was concluded that, the replacement of bread flour (WF) with up to $10 \%$ decorticated cracked broad beans flour produced acceptable Egyptian 'Balady' bread. Dhingra and Jood (2004), studied the effect of supplementation on baking characteristics of bread. they indicated that bread volume decreased with increasing amount of non-wheat flour substitution. They concluded that the substitution of wheat flour with soybean and barley flour up to an amount equivalent to $10 \%$ of full-fat and defatted soy flour, $15 \%$ for barley flour, full-fat soy + barley flour and defatted soy + barley flour produced acceptable bread loaves. Hooda and Jood (2005), developed wheat-fenugreek-based health bread; Used samples represented commonly grown varieties of wheat and fenugreek. They found that, additions of fenugreek (raw, soaked and germinated) up to the level of 15 per cent produced bread with a satisfactory loaf volume, whereas the 20 per cent level of supplementation caused a depression effect in loaf volume. Ribotta et al. (2005), examined the effect of several derivatives of soybean on dough properties and bread quality. They showed that, soy flours and soy protein isolates (SPIs) affected dough properties. Soy products were harmful to gluten formation, dough extensibility properties, gas retention properties and bread quality. Butt et al. (2011), made a study to investigate, partially replacing wheat flour with raw, germinated and fermented cowpea flour effects on baking and characteristics of bread .Raw, germinated and fermented cowpea flours were blended with wheat flour at 5,10,15 and 20\% substitution level. The obtained results showed that The bread volume decreased with increasing the cowpea flour substitution, while, the loaf weight increased. Substitution of wheat flour with cowpea flour also affected the sensory characteristics of bread. Replacement of wheat flour with cowpea flour up to $10 \%$ of substitution level produced acceptable bread. Mohammed et al. (2012), evaluated the effect of chickpea addition at different concentration on wheat dough rheology and bread characteristics. They used partial substitution of wheat flour with chickpea flour at the levels of 10, 20 and $30 \%$. They showed that, chickpea addition with $<20 \%$ significantly impaired the volume, internal structure, and texture of the breads. Roberts et al. (2012), substituted Fenugreek gum (extruded and non-extruded) for wheat flour at $0 \%, 5 \%$ and $10 \%$ (w/w). They found that, the substitution of FG into bread dough at levels of $10 \%$ caused detrimental results to baked bread volume, texture and the general appearance. Ahmed (2014), determined the effect of the partial replacement of wheat flour by lupine flour. They reached that, concentration of lupine flour up to $10 \%$ can be used successfully in bakery products. Menon and Majumdar (2015), studied the composite flours prepared using refined wheat flour (WF), high protein soy flour (SF), sprouted mung bean flour (MF) and mango kernel flour (MKF). Three variations were formulated such as V-I (WF: SF: MF: MKF=85:5:5:5), V-II (WF: SF: MF: MKF=70:10:10:10), and V-III (WF: SF: MF: MKF=60:14:13:13). They found that, the Physical characteristics of the bread variations revealed a percentage decrease in loaf height (14 $\%$ ) and volume $(25 \%)$ and $20 \%$ increase in loaf weight with increased substitution of composite flour. Lalit and Kochhar (2017), showed that, incorporation of barely flour at 25 percent level and germinated fenugreek seed powder at 5 percent level was highly acceptable.

Rai et al., 2012, reached that as the level of rice flour incorporation increased, a decrease in baking absorption, loaf weight, loaf volume was observed, although handling of dough was smooth for all levels of incorporation of rice flour. However, with $25 \%$ level of rice flour, the bread making quality was comparable with control flour, but further increase (more than $25 \%$ ) of alternate flour (cereals), significantly deteriorated the bread making quality of flour mixture. Rhee et al. (1982) reported that, loaf volume of bread prepared from barley-wheat blend was similar to the control. Bhatty (1986) studied that 50\% replacement of wheat flour with barley flour had no serious effects on loaf characters and was maximum at $25 \%$ level of incorporation of rice flour. Rao and Rao (1997), reported that the water absorption of flour blends and bread characters decreased with increasing level of sorghum substitution.

Our recent results coincide with the finding of literature regarding rice flour replacement. Tanaka (1972), studied the influenced of rice flour substitute on the baking quality of wheat flour and the method to improve the rice bread quality were examined. The results were as follows; (1) the baking quality of wheat flour and also the loaf volume are reduced by substituting rice flour to which the use of surfactant is effective, (2) extension of the 
final proofing time and the use of $\alpha$-amylase are effective to increase the loaf volume and (3) it was better not to reduce too much the size of rice flour particle. Islam et al. (2011), reached that, bread volume decreased, whereas, bread weight and moisture content increased with the increasing level of maize and brown rice flour. The crumb and crust color of breads were improved with addition of $8 \%$ maize and $8 \%$ brown rice flour in bread formulation. They also found that, the protein content and other nutrients of breads were increased by addition of maize and brown rice flours. Also, Bread quality in respects of bread volume and crumb texture were improved by using $2.5 \%$ yeast, $5 \%$ sugar, $5 \%$ fat and $0.6 \%$ improver. The analysis of bread containing added $8 \%$ maize and $8 \%$ brown rice flours showed protein of $9.76 \%$, fat of $4.10 \%$, ash of $2.10 \%$, crude fibre of $5.16 \%$, sugar of $2.26 \%$ and total carbohydrates of $46.91 \%$. Bread having $8 \%$ maize and $8 \%$ brown rice flour had the most acceptable flavour, texture, colour and overall acceptability when compared with other bread with maize and brown rice flour. Phimolsiripol et al. (2012), investigated the principal effect of adding rice bran to gluten-free (GF) bread (based on refined rice flour and a dough system of protein/emulsifier/hydrocolloid) and to adapt its recipe parameters - amount of egg albumen, emulsifier and hydroxypropyl methylcellulose. They showed that, supplementing GF bread with rice bran improved the final bread quality greatly, with darker colour of crust, higher specific volume and softer crumb firmness. The increased dietary fibre enhanced the nutritional profile of the GF breads. Selecting rice brans with high proportion of soluble dietary fiber (SDF) further improved bread parameters .These studies have clearly demonstrated the potential of selected rice bran fractions for developing high quality GF breads. Rai et al. (2012), determined proximate composition and pasting properties of raw materials, bread making quality and sensory qualities of breads produced from varying substitutions of rice flour and maize meal with wheat flour. They indicated that, the baking absorption was observed to increase with higher level of maize meal but it decreased when level of rice flour was increased. Loaf weight $(\mathrm{g})$ decreased with progressive increase in the proportion of maize meal but increased when rice flour incorporation was increased. Loaf volume, loaf height and specific volume decreased for progressively higher level of maize meal and rice flour. Khoshgozaran-Abras et al. (2014), indicated that, it was feasible to incorporate brown rice (BR) flour for baking Barbary flat bread; However, the threshold of BR flour addition should be $\leq 5 \%$. This is simply because, dough made from blend flour fortified with $5 \%$ BR flour, due to rheological evaluation, was strong and baked flat bread was highly ranked acceptable by panelists and re- mained fresher in comparison with other treatments by the end of storage.

As for sorghum flour supplementation, Bhatt and Gupta (2015), prepared Four different proportions of composite flours i.e., 1) $50 \%$ refined wheat, $10 \%$ chickpea, $10 \%$ buckwheat, $10 \%$ sorghum, $10 \%$ sprouted barley and $10 \%$ sprouted wheat (MI), 2) $50 \%$ whole wheat, $10 \%$ chickpea, $10 \%$ buckwheat $10 \%$ sorghum, $10 \%$ sprouted barley and $10 \%$ sprouted wheat (MII), 3) $65 \%$ refined wheat, $5 \%$ chickpea, $5 \%$ buckwheat $5 \%$ sorghum, $5 \%$ sprouted barley, $5 \%$ sprouted wheat, $5 \%$ corn flour and 5\% defatted soy flour (RWI), 4) $65 \%$ whole wheat, $5 \%$ chickpea, $5 \%$ buckwheat, $5 \%$ sorghum, $5 \%$ sprouted wheat, $5 \%$ sprouted barley, $5 \%$ corn flour and 5\% defatted soy flour (RWII). They concluded that, the use of the formulated composite flour might be considered in the preparation of the bread. The baking loss was found to be in the acceptable range. Sibanda et al. (2015) studied the effect of partial substitution of wheat flour with white grain sorghum flour on bread making. Composite flours containing $10 \%, 20 \%$ and $30 \%$ sorghum were used. There was a significant decrease in bread volume with sorghum replacement of higher than $20 \%$. The incorporation of sorghum at $10 \%$ produces bread of similar quality to wheat flour.

Concerning barley flour inclusion, Niffenegger (1964) showed that, the starch and proteins of barley and wheat flour behave differently. Baked products which are dependent on gluten-like strength are made less successfully from barley flour than from wheat flour. Sollars and Rubenthaler (1971) reported the role of starch in three soft wheat flour tests studied through the use of reconstituted flours. They showed that, reconstituted flour with barley starch proved very good for cakes and cookies ad had viscosities close to this of flour with wheat starch. These results indicate that starch must have certain physical and chemical properties for satisfactory performance. Dhingar and Jood (2002), found that, addition of $15 \%$ barley flour, $10 \%$ full fat soy flour, $10 \%$ defatted soy flour, $15 \%$ full fat soy flour+ barley flour and $15 \%$ defatted soy flour+ barley flour to wheat flour produce a product of acceptable quality. Dhingra and Jood (2004) found that, the bread volume decreased with increasing amount of nonwheat flour substitution. The crumb color changed from dreamish white to dull brown and a gradual hardening of crumb texture was observed as the addition of soybean (full-fat and defatted) and barley flours increased. It may be concluded that, the substitution of wheat flour with soybean and barley flour up to an amount equivalent to $10 \%$ of full-fat and defatted soy flour, $15 \%$ for barley flour, full-fat soy + barley flour and defatted soy + barley flour produced acceptable bread loaves with good organoleptic characteristics. Ereifej et al. 
(2006), reached that, when increasing barley flour content, the resulting bread loaves are found to be harder, darker in color, and non-uniformly shaped; therefore, less acceptable bread. Sullivan et al. (2010) suggested that, the inclusion of barley flour into the bread formulation would decrease the quality of the resulting breads. Increasing the pearled barley flour concentration significantly decreased the volume of the breads. Also, Hardness was found to increase significantly with an increased inclusion of barley flour .Lin et al. (2012) found that, increased levels of barley flour caused significant decreases in the specific volume, brightness and whiteness index of steamed bread, as well as increases in hardness and chewiness. Hussein et al. (2013)concluded that, wheat flour could be replaced with whole barely flour and gelatinized corn flour at the level of $30: 15 \%$ without drastic effect on the technological quality of bread. Moreover, higher nutritive values of this bread were achieved. Mariotti et al. (2014) showed that, the barley sourdoughs investigated could be used to obtain barley bread with enhanced nutritional value. Furthermore, despite the lower specific volume and denser crumb of barley breads with respect to wheat bread, no significant differences were seen in the degree of liking among the three breads after baking.

\section{Conclusion}

The obtained results might be summarized in the following:

\section{Loaf diameter before baking:}

1- Raising the level of rice flour substitution to $20 \%$ gave lower loaf diameter relative to $10 \%$ rice flour level $(20.22 \mathrm{vs.} 21.04 \mathrm{~cm}$ for 20 and $10 \%$ rice flour substitution levels, respectively). This might indicate an increase in dough elasticity (loaf shrunk). Also, the addition of $5 \%$ fenugreek flour to blend of $20 \%$ rice flour, gave substantial reduction in loaf diameter $(19.78 \mathrm{~cm})$. While, the least significant loaf diameter was expressed by the blend of $20 \%$ rice flour $+5 \%$ soybean flour $+75 \%$ wheat flour $(18.63 \mathrm{~cm})$.

2- Increasing the level of sorghum flour substitution to wheat flour in the blend to $30 \%$ gave lower dough elasticity (larger loaf diameter) relative to $20 \%$ level of substitution. In the meantime, figures of loaf diameter for $30 \%$ sorghum flour blends were significantly similar to full wheat flour and blends with $10 \%$ sorghum flour substitution.

3- Barley flour substitution to wheat flour at $20 \%$ level gave lower loaf diameter $(19.60 \mathrm{~cm})$. Additional substitution of wheat flour by $5 \%$ fenugreek flour or $5 \%$ soybean flour, significantly improved dough elasticity (reduced loaf diameter) $(17.29$ and $17.64 \mathrm{~cm}$ for the former and latter blends, respectively).
4- Wheat flour blends that contained $10 \%$ sorghum flour vs. $20 \%$ sorghum flour showed a reduction in loaf diameter reached $1.796(\mathrm{p} \geq 0.001)$, $0.789(\mathrm{p} \geq 0.007)$ and $0.199(\mathrm{p} \geq 0.381) \mathrm{cm}$ for Misr2, Giza171 and Gimmeza11 wheat cultivars, respectively). Whereas, comparison between $20 \%$ vs. $30 \%$ sorghum flour substitution over pulses flours, showed an increase in loaf diameter of Misr2 blends (1.703 $\mathrm{cm} \mathrm{p} \geq 0.001)$, Giza171 blends $(0.944 \mathrm{~cm} \mathrm{p} \geq 0.001)$ and Gimmeza11 (0.635 $\mathrm{p} \geq 0.05)$. This might indicate a loss of dough elasticity when sorghum flour substitution level surpasses $20 \%$ of the blend.

5- Comparison between blends with $10 \%$ vs. $20 \%$ barley flour showed reduction in loaf diameter reached $2.103 \quad(\mathrm{p} \geq 0.001)$ for Misr2 blends, $0.418 \mathrm{~cm}(\mathrm{p} \geq 0.145)$ for Giza171, whereas, loaf diameter increased by $0.366(\mathrm{p} \geq 0.26)$ in Gimmeza11 wheat blends. Comparison between $20 \%$ vs. $30 \%$ barley flour substitution levels, showed an increase in loaf diameter with increasing substitution level reached 1.819 $(p \geq 0.001)$ for Misr2, $1.150 \mathrm{~cm}(p \geq 0.001)$ for Giza171 and $0.061 \mathrm{~cm}(\mathrm{p} \geq 0.03)$ for Gimmeza11.

6- Rice flour blends had higher loaf diameter by $0.374 \mathrm{~cm} \quad(p \geq 0.003)$ for Misr2, $0.717 \mathrm{~cm}$ ( $\mathrm{p} \geq 0.001$ ) for Giza171, whereas, blends with Gimmeza11 wheat cultivar respond differently. The difference between blends with rice flour $v s$. Blends with barley flour, showed larger loaf diameter for blends with rice flour reached $0.567(p \geq 0.001), \quad 0.378 \quad(p \geq 0.02)$ and 0.164 $(\mathrm{p} \geq 0.78)$ for Misr2,

\section{Loaf diameter after baking:}

7- It was valuable to notice that loaves made from full wheat flour, expressed values of loaf diameter after baking of larger magnitude than those expressed by flour blends that contained 10 or $20 \%$ rice flour.

8- Raising the level of sorghum flour substitution to $20 \%$, gave the least significant figures for the loaf diameter after baking (17.46, 17.40 and $16.89 \mathrm{~cm}$ for blends of wheat flour $+20 \%$ sorghum flour, wheat flour, wheat flour $+20 \%$ sorghum flour $+5 \%$ fenugreek flour and wheat flour $+20 \%$ sorghum flour $+5 \%$ soybean flour, respectively). Additional substitution by a higher level of sorghum flour reached $30 \%$ whether alone or with $5 \%$ pulses flourmaintained loaf diameter after baking to a level like that of full wheat flour.

9- Gimmeza11 wheat flour blend with $20 \%$ barley flour maintained higher loaf diameter (20.14 $\mathrm{cm})$. Addition substitution by $5 \%$ fenugreek or $5 \%$ soybean flour to wheat $20 \%$ barley flours blends, resulted in significantly lower loaf diameter after baking (16.22 and $16.55 \mathrm{~cm}$ for blend of $20 \%$ barley flour $+5 \%$ fenugreek 
flour and $20 \%$ barley flour $+5 \%$ soybean flour, respectively).

10 - blends that contained $5 \%$ fenugreek $+5 \%$ soybean flours gave narrower loaf diameter in blends in Misr2 and in blends of Giza171, While, blends of Gimmeza11 flours besides fenugreek and soybean flours gave larger loaf diameter after baking.

\section{Loaf weight after baking:}

11- Loaf weight after baking associated with $10 \%$ level of substitution surpassed those of $20 \%$ level by 3.69 g. $(\mathrm{p} \geq 0.001), 3.614$ g. $(\mathrm{p} \geq$ $0.0001)$ and 4.201 g. $(\mathrm{p} \geq 0.0001)$ for Misr2, Giza171 and Gimmeza11 wheat cultivar flours, respectively. Contrary, raising the level of sorghum flour substitution to $30 \%$ in comparison to $20 \%$ level showed that loaf weight after baking increased with increasing the level of substitution to $30 \%$ level as 4.426 g. ( $p \geq$ $0.0001)$ for Misr2, $4.004 \mathrm{~g}(\mathrm{p} \geq 0.0001)$ for $\mathrm{Gi}^{-}$ za171 and $3.930 \mathrm{~g}$. ( $\mathrm{p} \geq 0.0001)$ for Gimmeza11, respectively.

12- Flour blends with $10 \%$ level of barley flour substitution yielded heavier loaf weight relative to blends with $20 \%$ level of barley flour substitution. Substantial increase in loaf weight after baking was associated with barley substitution level of $30 \%$.

13- Blends of Misr2 wheat substituted with rice flour had heavy loaf weight over blends substituted with sorghum flour. While, the opposite was true with blends of Giza171 and Gimmeza11. Also, comparison between blends substituted with rice flour and those substituted by barley flour showed an increase in loaf weight after baking with barley flour with Misr2 cultivars. While, vas versa were noticed with $\mathrm{Gi}$ za171 and Gimmeza11.

14- Wheat flour blends with local cereals substitution and fenugreek flour versus those with soybean flour showed a superiority of the former in loaf weight after baking over the latter for Misr2 cultivar and a reduction for Giza171 and for Gimmeza11 cultivar.

\section{REFERENCE}

Abdel-Kader, Z.M. (2000).Enrichment of Egyptian 'Balady' bread.Part 1. Baking studies, physical and sensory evaluation of enrichment with decorticated cracked broad beans flour (Viciafaba L.). Nahrung 44 Nr. 6, S. 418-421.

Ahmed, A.R. (2014). Influence of Chemical Properties of Wheat-Lupine Flour Blends on Cake Quality. American Journal of Food Science and Technology, 2 (2): 67-75.

Butt, M.S., J. Iqbal, A. Naz, H.A.R. Suleria1, M.M.N. Qayyum, Faiza Saleem and M.A. Jahangir (2011).Effect of Flour Blending on
Bread Characteristics. Internet Journal of Food Safety, 13: 142-149

Bhatt, S.M. and R.K. Gupta (2015).Bread (composite flour) formulation and study of its nutritive, phytochemical and functional properties. Journal of Pharmacognosy and Phytochemistry; 4(2): 254-268.

Dhingar, S. and S. Jood (2002).Physico-chemical and nutritional properties of cereal- pulse blends for bread making.Nutrition and Health, 16:183-194.

Dhingra S. and S. Jood (2004).Effect of flour blending on functional, baking and organoleptic characteristics of bread. International Journal of Food Science and Technology, 39:213-222.

Ereifej, K.I., M.A. Al-Mahasneh and T.M. Rababah (2006).Effect of barley flour on quality of balady bread. International Journal of Food Properties, 9: 39-49.

Harinder, K., B. Kaur and S. Sharma (1999). Studies on the baking properties of wheat: $\mathrm{Pi}$ geonpea flour blends. Plant Foods for $\mathrm{Hu}-$ man Nutrition, 54: 217-226.

Hruskova, M., I. Svec and I. Kucerova (2003).Effect of malt flour addition on the rheological properties of wheat fermented dough. Czech J. Food Sci., 21(6): 210-218.

Hooda, S. and S. Jood (2005).Effect of fenugreek flour blending on physical, organoleptic and chemical characteristics of wheat bread. Nutrition \& Food Science, 35 (4): 229-242.

Hadnađev, T.D., A. Torbica and M. Hadnađev (2011).Rheological properties of wheat flour substitutes/alternative crops assessed by Mixolab. Procedia Food Sci., 1: 328334.

Hussein, A.M.S., M.M. Kamil, Nefisa A. Hegazy, S.A.H. Abo El-Nor (2013). Effect of Wheat Flour Supplemented with Barely and/or Corn Flour on Balady Bread Quality. Pol. J. Food Nutr. Sci., 63 (1): 11-18.

Islam, M.Z., M. Shams-Ud-Din and M.A. Haque (2011).Studies on the effect of brown rice and maize flour on the quality of bread.BangladeshAgril. Univ. 9(2): 297304.

Khoshgozaran-Abras, S., M. H. Azizi, N. Bagheripoor-Fallah and A. Khodamoradi (2014).Effect of brown rice flour fortification on the quality of wheat-based dough and flat bread. J. Food Sci. Technol., 51 (10): 2821-2826.

Lin, S.Y., H.H. Chen, S. Lu and P.C. Wang (2012). Effects of blendings of wheat flour with barely flour on dough and steamed bread properties. Journal of Texture Studies 43:438- 444 . 
Lalit, H. and A. Kochhar (2017). Development and organoleptic evaluation of bread formulated by using wheat flour, barley flour and germinated. Chem. Sci. Rev. Lett., 6(23): 1728-1734.

Mariotti, M., C. Garofalo, L. Aquilanti, A. Osimani, L. Fongaro, S.Tavoletti, Anna-Sophie Hager and F.Clementi (2014). Barley flour exploitation in sourdough bread-making: A technological, nutritional and sensory evaluation. LWT - Food Science and Technology, 59(2): 973-980.

Menon, L. and S.D. Majumdar (2015). Development and analysis of composite flour bread. J. Food Sci. Technol., 52(7): 4156-4165.

Mohammed, I., A.R. Ahmed, B. Senge (2012). Dough rheology and bread quality of wheat-chickpea flour blends. Industrial Crops and Products 36:196-202.

Niffenegger, E.V. (1964),chemical and physical characteristics of barley flour as related to its use in baked products. A thesis submitted to the Graduate Faculty in partial fulfillment of the requirements for the degree of Master of Science in Home Economics, Montana State College Bozeman, Montana.

Navickis, L. L. (1987). Corn Flour Addition to Wheat Flour DoughsEffect on Rheological Properties. Cereal Chemists, 64(5): 307310.

Phimolsiripol, Y., A. Mukprasirt and R. Schoenlechner (2012).Quality improvement of rice-based gluten-free bread using different dietary fibre fractions of rice bran. Journal of Cereal Science 56: 389-395.

Ribotta, P.D, S.A. Arnulphi, A.E. León and M.C. Añón (2005).Effect of soybean addition on the rheological properties and breadmaking quality of wheat flour. J Sci Food Agric 85:1889-1896.

Roberts, K.T., S.W. Cui, Y.H. Chang, P.K.W. Ng and T. Graham (2012). The influence of fenugreek gum and extrusion modified fen- ugreek gum on bread. Food Hydrocolloids 26: $350-358$.

Rai, S., A. B. Kaur, K.S. Singh and Minhas (2012).Quality characteristics of bread produced from wheat, rice and maize flours. Food Sci Technology, 49(6): 786789.

Sollars, W.F. and G.L. Rubenthaler (1971). Performance of wheat and other starches in reconstituted flours. Wheat and Starches in Flours, 48: 397- 410.

Sharma, S., U. Bajwa and H.P.S. Nagi (1999). Rheological and baking properties of cowpea and wheat flour blends. J. Sci. Food Agric., 79:657-662.

Sharma S, U. Bajwa H. Nagi (1999). Rheological and baking properties of cowpea and wheat flour blends. J Sci Food Agric 79(5):657662.

Sullivan, P., J. O'Flaherty, N. Brunton, E. Arendt and E. Gallagher (2010). Fundamental rheological and textural properties of doughs and breads produced from milled pearled barley flour. Eur Food Res. Technol., 231: 441-453.

Sibanda, T., T. Ncube and N. Ngoromani (2015).Rheological Properties and Bread Making Quality of White Grain SorghumWheat Flour Composites.International Journal of Food Science and Nutrition Engineering, 5(4): 176-182.

Tanaka, Y. (1972).Quality Improvement of Rice Bread. Jarq J., 6(3): 181-187.

Vásquez, F., S. Verdú, Alma R. Islas., José M. Barat and R. Grau (2016).Effect of low degrees of substitution in wheat flour with sorghum, oat or corn flours on physicochemical properties of composite flours. Food Science and Technology, 2: 1-12.

Yaseen, A.A., A. Sh. Abd-El-Hafeez and M.S. Mostafa (2007).Egyptian balady bread and biscuit quality of wheat and Triticale flour blends. Pol. J. Food Nutr. Sci., 57 (1): 2530 . 


\section{استبدال دقيق القمح بدقيق الحبوب و البقول المحليه كاسلوب للتغلب على مشكلة نقص الحبوب بمصر ب - مودة الخبز البلدى}

زينب رافت عطيه و مسعد عبد السيد الجنبيهى و محمد عبد الستار احمد

تضمنت الدراسة الحالية بحث إمكانية إحلال دقيق الحبوب المحلية (الذرة الرفيعة والثعير العاري عند صناعة الخبز البلدي من أصناف القمح المحلية. وقد تضمنت أيضاً إضافة دقيق كلا من الحلبة المحلية وفول الصويا المستورد لتحسين خواص الخبز. أجريت تجارب منفردة لكل صنف من أصناف القدح وقد شملت أصناف القهح

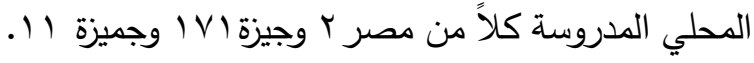
وقد تم الحصول على المواد الخام جميعها من مركز البحوث الزراعية التابع لوزارة الزراعة بالجيزة - مصر .

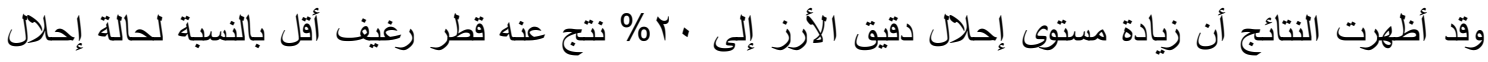

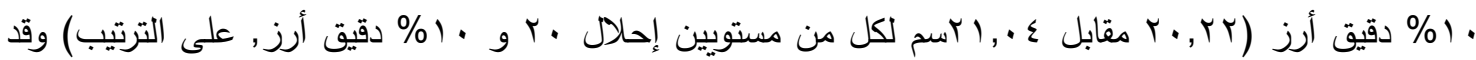

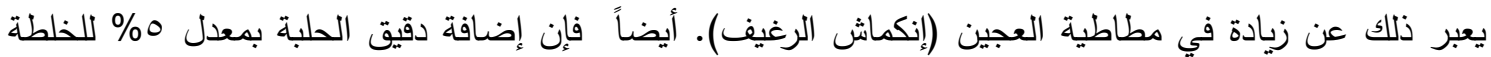

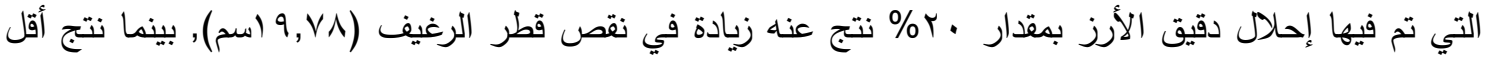

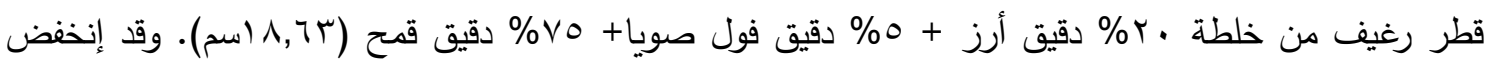

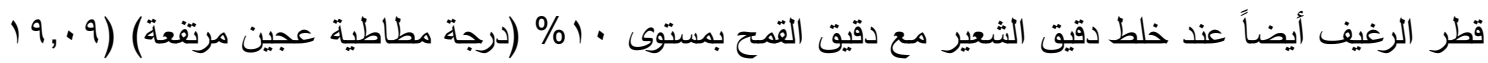

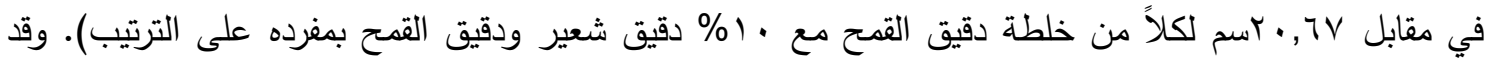
أدى إستبدال دقيق القيح بمستوى 0\% دقيق حلبة مع •1\% دقيق شعير إلى إنخفاض في مطاطية الدقيق (قطر

$$
\text { رغيف أكبر )( § §, • باسم). }
$$

وفي ذات الوقت فإن إستبدال دقيق القـح بـ 0\% دقيق صويا + · ( \% دقيق شعير نتج عنه نقص شديد في

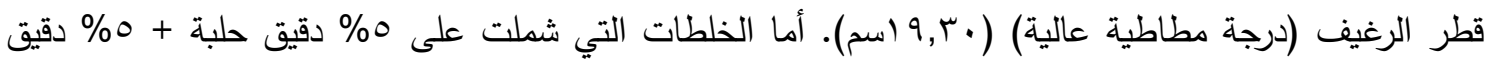

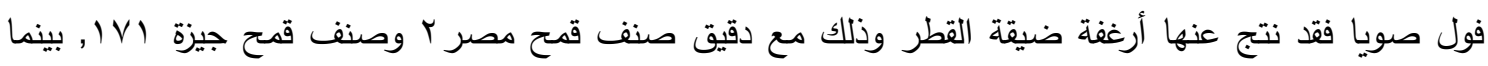

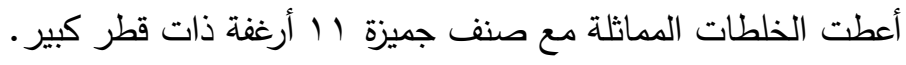

خلطات دقيق صنف القهح مصر r مع دقيق الأرز إمتازت بزيادة وزن الرغيف بعد الخبيز مقارنة بالخلطات

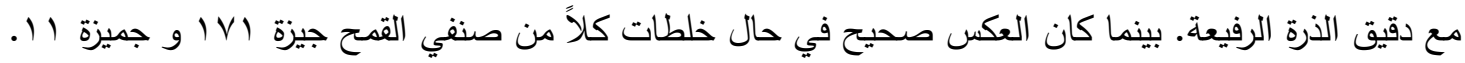
أيضاً فإن الدقارنة بين الخلطات التي تم فيها الإحلال بدقيق الأرز والخلطات التي تم فيها الإحلال بدقيق

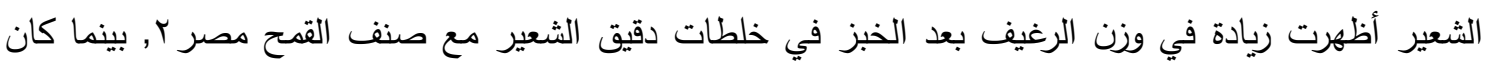

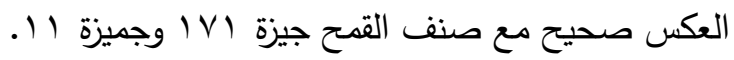

خلطات دقيق القدح التي تم فيها الإستبدال بالحبوب المحلية ودقيق الحلبة مقارنة بمثيلتها التي تم فيها إستبدال دقيق فول الصويا أظهرت تفوق الأولى على الثانية في صفة وزن الرغيف بعد الخبز في حالة صنف القهح مصر r

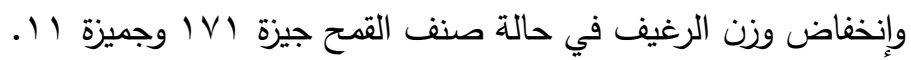

